Article

\title{
Variability of Chlorophyll-a and Secchi Disk Depth (1997-2019) in the Bohai Sea Based on Monthly Cloud-Free Satellite Data Reconstructions
}

\author{
Junting Guo ${ }^{1,2}$, Jingfang Lu ${ }^{1,2}$, Yuming Zhang ${ }^{3}$, Chen Zhou ${ }^{4}$, Shufang Zhang ${ }^{5, *}$, Daosheng Wang 6 \\ and Xianqing $\mathrm{Lv}^{1,2}$
}

check for updates

Citation: Guo, J.; Lu, J.; Zhang, Y.; Zhou, C.; Zhang, S.; Wang, D.; Lv, X. Variability of Chlorophyll-a and Secchi Disk Depth (1997-2019) in the Bohai Sea Based on Monthly

Cloud-Free Satellite Data

Reconstructions. Remote Sens. 2022 14, 639. https://doi.org/10.3390/ rs14030639

Academic Editor: Jose Moreno

Received: 29 December 2021

Accepted: 24 January 2022

Published: 28 January 2022

Publisher's Note: MDPI stays neutral with regard to jurisdictional claims in published maps and institutional affiliations.

Copyright: (C) 2022 by the authors. Licensee MDPI, Basel, Switzerland. This article is an open access article distributed under the terms and conditions of the Creative Commons Attribution (CC BY) license (https:// creativecommons.org/licenses/by/ $4.0 /)$.
1 Physical Oceanography Laboratory/CIMST, Ocean University of China, Qingdao 266100, China; guojunting@stu.ouc.edu.cn (J.G.); lujingfang@stu.ouc.edu.cn (J.L.); xqinglv@ouc.edu.cn (X.L.)

2 Qingdao National Laboratory for Marine Science and Technology, Qingdao 266100, China

3 South China Institute of Environmental Sciences, Ministry of Ecology and Environment of the People's Republic of China, Guangzhou 510530, China; zhangyuming@scies.org

4 School of Marine Science, Nanjing University of Information Science and Technology, Nanjing 210044, China; 20201209018@nuist.edu.cn

5 National Marine Environment Monitoring Center, Dalian 116023, China

6 Hubei Key Laboratory of Marine Geological Resources, China University of Geosciences, Wuhan 430074, China; wangds@cug.edu.cn

* Correspondence: sfzhang@nmemc.org.cn

\begin{abstract}
Ocean colour data are crucial for monitoring and assessing marine ecosystems. In this study, the Data Interpolating Empirical Orthogonal Functions (DINEOF) approach was applied to the Ocean Colour Climate Change Initiative (OC-CCI), chlorophyll-a (Chl-a) and Secchi disk depth $(Z s d)$ to completely reconstruct the missing pixels in the Bohai Sea during 1997-2019. The results of cross-validation demonstrate that the DINEOF reconstructed data have a good agreement with the satellite-measured data. Based on monthly cloud-free satellite data reconstructions, the Zsd series showed high negative correlation with $\log 10$ (Chl-a). The Zsd as a function of log10 (Chl-a) can be well fitted by the cubic polynomial in the offshore waters. The Chl-a in the entire Bohai Sea showed a significant decreasing trend $\left(-0.013 \mathrm{mg} / \mathrm{m}^{3} /\right.$ year $)$, while the $\mathrm{Zsd}$ exhibited a significant increasing trend $(0.0065 \mathrm{~m} /$ year), and both had regional-seasonal variations. In addition, the ensemble empirical mode decomposition (EEMD) results reveal highly nonlinear trends of Chl-a and Zsd. The linear and nonlinear trends of Chl-a and Zsd suggest the deterioration of water quality in the Bohai Sea was not continued over the past two decades. This study presents the first simultaneous investigation of Chl-a and Zsd using the 23 years of cloud-free reconstructions in the Bohai Sea.
\end{abstract}

Keywords: Data Interpolating Empirical Orthogonal Functions (DINEOF); Bohai Sea; chlorophyll-a (Chl-a); Secchi disk depth (Zsd); water quality; remote sensing

\section{Introduction}

Chlorophyll-a (Chl-a) and Secchi disk depth $(\mathrm{Zsd})$ are two important indicators to quantify water quality. Chl-a is considered a proxy for phytoplankton biomass in primary productivity studies [1-3]. Meanwhile, the Zsd is the oldest oceanographic variable, recorded since the nineteenth century to provides a reading of water transparency [4-6]. Traditional measurements of Chl-a and Zsd are sparse and laborious, and thus are not helpful for performing spatio-temporal analyses of large-scale water bodies. With the development of ocean color satellite sensors, remote sensing techniques have been widely used to investigate the Chl-a and Zsd, providing global and repetitive measurements [7-9]. Lee et al. [10] validated an empirical relationship between Chl-a and Zsd for Case-1 waters, thus indicating that historical Zsd datasets were useful to infer the variability in phytoplanktonic 
content. Since the launch of the CZCS in the 1970s, more and more single-sensor satellite sensors (e.g., SeaWiFS; MODIS; MERIS; GOCI; OC5) have produced Chl-a and remote-sensing reflectance $(R r s)$ products at global and regional scales (http:/ / oceancolor.gsfc.nasa.gov (accessed on 29 December 2021)). According to the new underwater visibility theory, Lee et al. [11] established an innovative semi-analytical model to estimate Zsd from Rrs for the global ocean which was recently validated with a large number of in situ measurements in the China seas [8].

Compared with single-sensor satellite datasets, the European Space Agency (ESA) Ocean Colour Climate Change Initiative (OC-CCI) datasets have longer time series, higher pixel coverage and more careful sensor inter-calibration $[6,9,12,13]$, which reduce spurious trends in the derived Chl-a and Zsd. The OC-CCI version 4.2 project aims to provide the highest quality ocean colour data over Case-1 and Case- 2 waters by band-shifting and bias-correcting MERIS, MODIS and VIIRS data to match SeaWiFS data [13]. The study of Chl-a and Zsd in the coastal waters is of great significance to aquatic ecosystems and the variability of water properties. The Bohai Sea (Figure 1), one of the most turbid seas in the world, is under severe stresses from human factors. Fishery biomass in 1998 was only 5\% of what it was in 1959 [14,15], and the volume of the sewage water that flowed into the Bohai Sea was $\sim 8.9 \times 10^{10} \mathrm{~m}^{3}[16,17]$. In addition, Ning et al. [18] reported that inorganic nitrogen and salinity showed an increased trend in the Bohai Sea over the period 1960-1996. Therefore, it is of great significance to perform a detailed evolution of the change in water quality over the past 20 years.
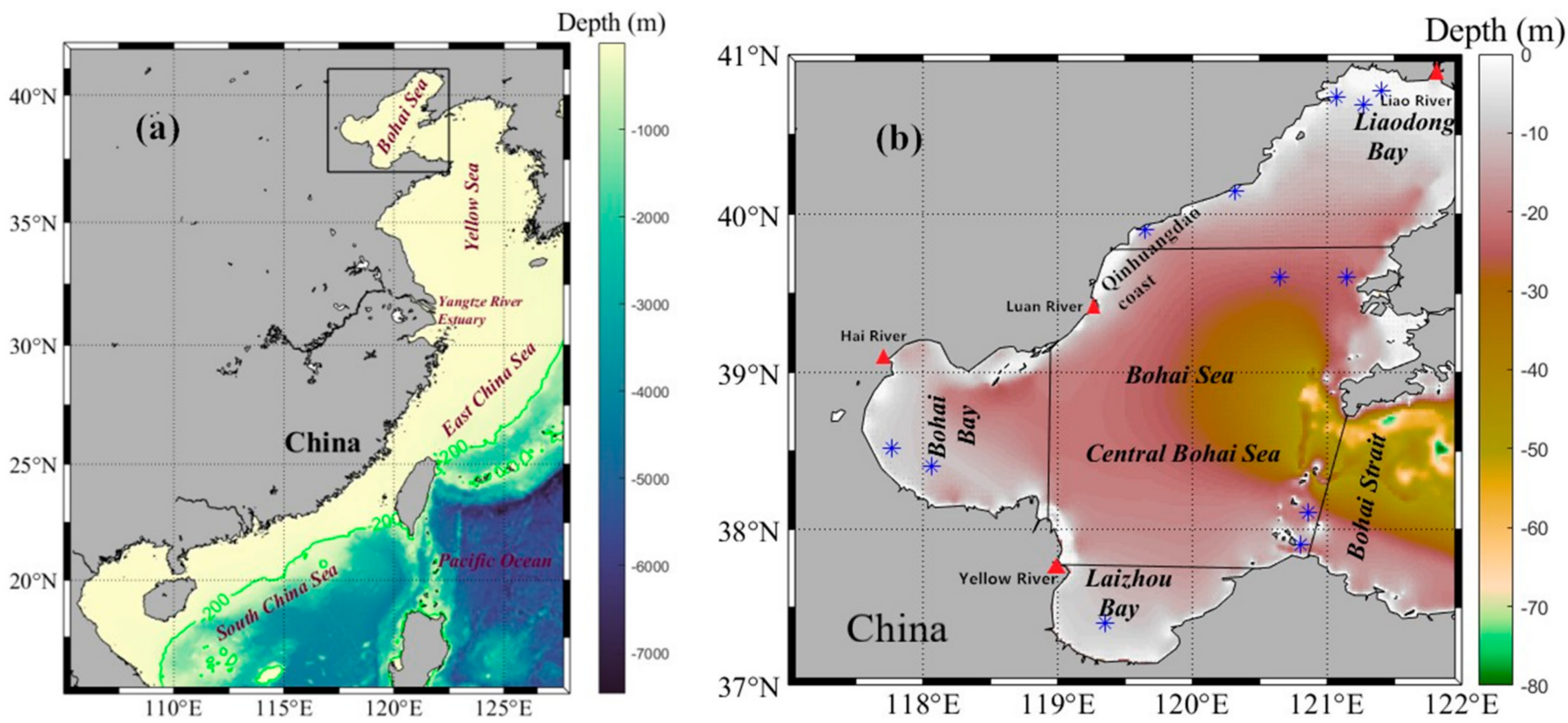

Figure 1. Location (a) and bathymetry (b) of the Bohai Sea. The demarcation line of each sea area and Chl-a match-up in (b) are represented by black lines and blue asterisks, respectively.

Like the SeaWiFS, MODIS, MERIS, GOCI and OC5 datasets, there also exist missing pixels in the OC-CCI products due to cloud cover and other reasons $[19,20]$, which results in the loss of some local information and uncertainties in trend estimates in the Bohai Sea. To overcome the cloud-cover problem in the OC-CCI data, the Data Interpolating Empirical Orthogonal Function (DINEOF) was applied to derive the cloud-free Chl-a and Zsd for the Bohai Sea [21-23]. The DINEOF method utilizes the spatio-temporal coherency of the data to estimate the missing values, and has been successfully applied to various ocean color data, including Chl-a, the diffuse attenuation coefficient $(K d)$, satellite-derived sea surface temperature (SST) and normalized water-leaving radiance spectra (e.g., [19,20,24-26]). It is about 30 times faster than the widely used local optimal interpolation method [27], and has 
been proven to be reliable when compared with in situ observations [22,24]. In addition, the DINEOF method for remote sensing data was verified in a wide range of water types, such as the South China Sea, the eastern China seas, the Adriatic Sea, the Gulf of Maine, and globally [19,20,24-26]. Compared with traditional interpolation methods (e.g., [28-30]), the DINEOF method exploits major empirical orthogonal function (EOF) modes to estimate the missing data, which is more suitable for a large number of grids [25].

Previous studies of the Bohai Sea focused on different topics, such as the spatial and seasonal variations of $\mathrm{Chl}-\mathrm{a}$ and $\mathrm{Zsd}$ and the potential drivers related to the linear trends of Chl-a and Zsd (e.g., [3,14,31-37]). With the 12-year MODIS Chl-a, Fu et al. [3] investigated the spatio-temporal variations of Chl-a in the entire Bohai Sea. Zhai et al. [37] studied the influence of SST, land rainfall, river runoff and the Pacific Decadal Oscillation on the linear trend of Chl-a in the Bohai Sea. Based on monthly MODIS Rrs, Shang et al. [14] reported that no significant trend of Zsd was found in the central Bohai Sea in 2003-2014. Zhou et al. [34] carried out an EOF analysis of Zsd over the Bohai Sea and the Yellow Sea, indicating that the Zsd variations were strongly correlated with suspended matter concentration. These findings have greatly improved our knowledge about the spatio-temporal patterns of Chl-a and Zsd in the Bohai Sea. However, previous satellite Chl-a and Zsd findings in the Bohai Sea covered a relatively short span of time and were analyzed separately. Moreover, the linear trend usually accounts for a small part of the total variance in the time series data, while the underlying mechanism is likely to be nonlinear and nonstationary [38]. At present, some fundamental issues in the Chl-a and Zsd are still poorly resolved, leading to various questions. Do the Chl-a and Zsd in the Bohai Sea have some relationship, and what is it? How have the Chl-a and Zsd changed in the Bohai Sea over the past two decades? Are the variations of the Chl-a and Zsd homogenous in the central Bohai Sea and three bays?

To explore these issues, in this study, we: (1) derived the monthly cloud-free Chl-a and Zsd between 1997 and 2019 in the Bohai Sea, based on the DINEOF method and OC-CCI products; (2) investigated the long-term relationship among the Chl-a and Zsd in the Bohai Sea; and (3) explored the linear and nonlinear variations of the Chl-a and Zsd in the central Bohai Sea and three bays.

\section{Materials and Methods}

\subsection{Study Area}

The Bohai Sea is a large and semi-closed inland sea surrounded by one of the most heavily industrialized regions in China, with an average water depth of $18 \mathrm{~m}$ [14]. It includes three bays (Bohai Bay, Liaodong Bay and Laizhou Bay), which are primary recipients of more than 17 rivers [39]. Among these rivers, the Huanghe River, Luanhe River, Haihe River and Liaohe River are the four major rivers flowing into the Bohai Sea, providing substantial land-sourced nutrients to support phytoplankton growth, and aggravating ocean eutrophication $[36,37]$. The central Bohai Sea connects to the Yellow Sea through the Bohai Strait with the deepest part of $\sim 70 \mathrm{~m}$.

\subsection{In Situ Data}

In situ surface Chl-a data were used for evaluating the OC-CCI Chl-a data. These samples were collected by the State Oceanic Administration of China during 2018-2019. For the Chl-a analysis, seawater samples at the surface $(0.5 \mathrm{~m})$ were collected using sampling bottles and then filtered through cellulose acetate filters under low vacuum pressure. Finally, the concentration was determined by the fluorometric method [32,40]. This method has an uncertainty of about $10 \%$.

\subsection{Satellite Data}

In this study, the ESA-OC-CCI version 4.2 monthly $R_{r s}$ and Chl-a data with a spatial resolution of 2.5 arcmin from September 1997 to December 2019 in the Bohai Sea were downloaded from https:/ / esa-oceancolour-cci.org/ (accessed on 29 December 2021). $R_{r s}$ values were provided for the standard SeaWiFS wavelengths $(412,443,490,510,555$, 
$670 \mathrm{~nm}$ ) with pixel-by-pixel uncertainty estimates for each wavelength. Every downloaded dataset included an image of bias estimates in $R_{r s}$, from which the monthly unbiased $R_{r s}$ was obtained [41]. Chl-a was estimated using a blended combination of OC3, OCI (OC4 + CI) and OC5 algorithms, and the blended chlorophyll algorithm improves performance in the coastal waters [13]. Further information on the OC-CCI products can be referred to the Product User Guide [13].

\subsection{Methods}

\subsubsection{Empirical Correction of the OC-CCI Chl-a}

Although the optically complex properties of the Bohai Sea usually lead to an overestimation of the standard Chl-a $[32,33,42,43]$, highly significant positive correlations between the in situ and OC-CCI observations haven been found in many coastal regions [43-45]. Numerous studies have reported that the OC-CCI Chl-a products can be used properly for evaluating the Chl-a in the turbid marginal sea (e.g., [43-49]). In optically complex coastal waters, linear regression adjustments in log10-transformed mode will improve the consistency between the in situ and OC-CCI Chl-a $[9,47,49]$. Based on strict valid match-ups for SeaWiFS, He et al. [50] suggested that the satellite Chl-a of the Bohai Sea can be corrected using the linear scaling correction of $\log 10\left(C h l-a_{C}\right)=1.2904 \times \log 10(C h l-a)-0.4214$, where Chl-a $\mathrm{a}_{\mathrm{C}}$ is the Chl-a concentration after correction. Since the OC-CCI Rrs can be considered to be the same as SeaWiFS products [13], a statistical regression adjustment was performed to calibrate the OC-CCI Chl-a in the Bohai Sea [50].

\subsubsection{Algorithm to Retrieve Zsd}

With the semi-analytical model developed by Lee et al. [11], monthly estimated Zsd between 1997 and 2019 in the Bohai Sea can be calculated as

$$
Z_{s d}=\frac{1}{2.5 \operatorname{Min}\left(K_{d}\right)} \ln \left(\frac{\left|0.14-R_{r s}^{\prime}\right|}{0.013}\right)
$$

where $R_{r s}^{\prime}$ is taken as the $R_{r s}$ value corresponding to the wavelength with minimum $K_{d}$. In this study, two steps were applied to obtain $K_{d}$ in Equation (1): (1) firstly, version 6 of the Quasi-Analytical Algorithm is used to retrieve the total absorption $(a)$ and backscattering $\left(b_{b}\right)$ coefficients from the $R_{r s}$ [51], it should be noted that the input $R_{r s}$ is empirically corrected for Raman scattering [41,52]; (2) secondly, following the IOP-based model [52], the $K_{d}$ at SeaWiFS wavelengths can be estimated from $a$ and $b_{b}$. Details of the semi-analytical model can be obtained by reference to Lee et al. [11].

\subsubsection{Gap-Filling of the OC-CCI Data}

As shown in Figure 2, the percentage of available Chl-a and Zsd data in the Bohai Sea is uneven in both time and space, which may result in the loss of some important local information, especially in the three bays. In this study, the DINEOF method was applied to reconstruct missing data in monthly OC-CCI Chl-a and Zsd between 1997 and 2019 in the Bohai Sea. Prior to reconstruction, monthly images with less than $5 \%$ data coverage (the data coverage for each image was the ratio of available pixels to the sum of all pixels) and pixels with less than $10 \%$ coverage (the pixel coverage was the number of available images for each pixel divided by all valid images) from images were removed prior to processing to ensure an accurate reconstruction [23]. As a result, 268 monthly OC-CCI maps for both Chl-a and Zsd were used. Since the Chl-a products were usually log-normally distributed, it should be noted that Chl-a data were log10-transformed before the DINEOF reconstruction $[20,37,53]$. The DINEOF method applied here is the same as that of Li and He [24], including the given number of EOFs and convergence threshold. 

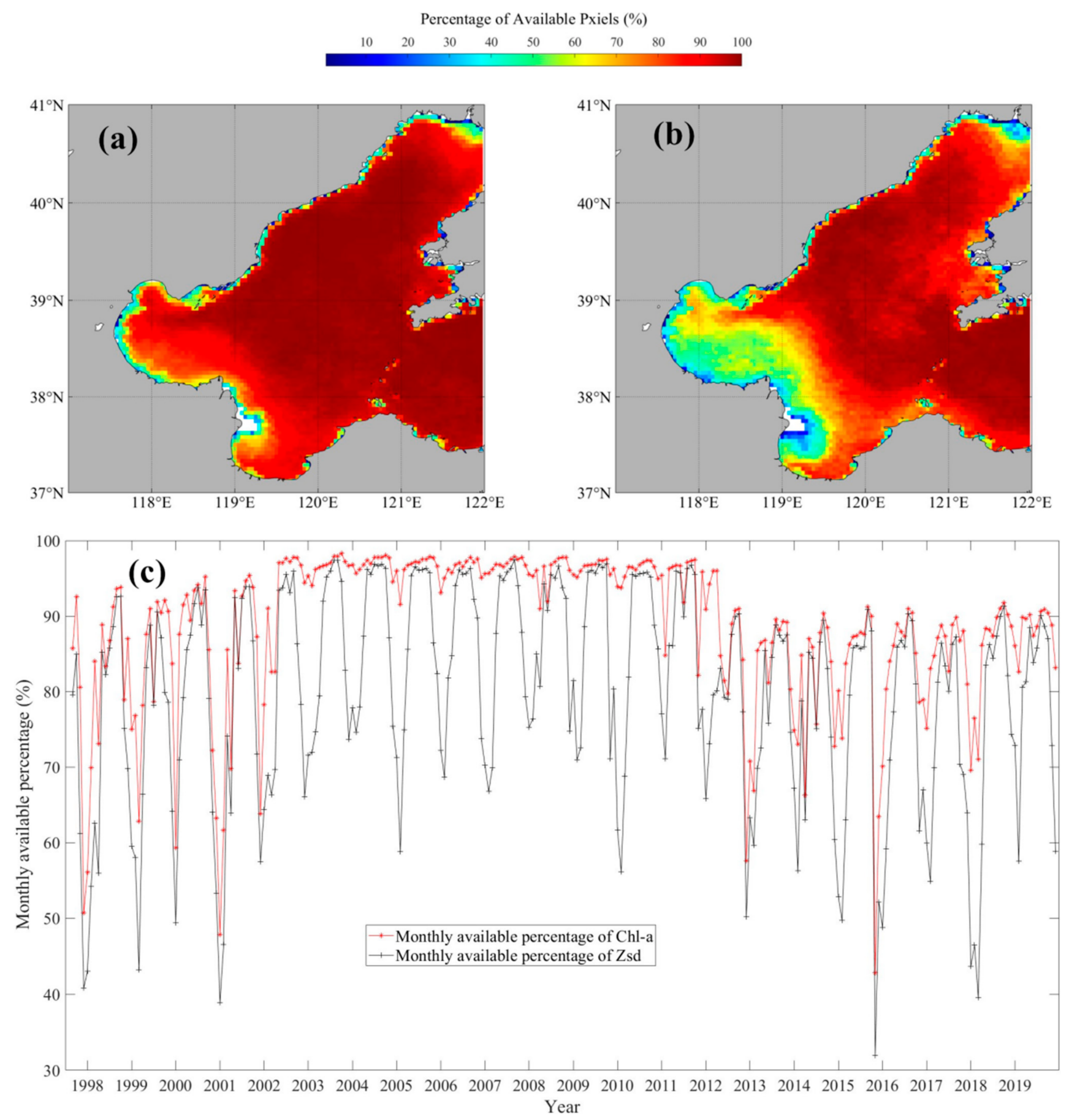

Figure 2. Spatial distribution of the percentage of available (a) Chl-a and (b) Zsd between 1997 and 2019. (c) Time series of the percentage of available Chl-a and Zsd over the Bohai Sea.

\subsubsection{Calculation of Linear Trend}

The linear trends of monthly variables were calculated as follows: (1) subtract climatological monthly values from the original monthly means (producing Chl-a and Zsd anomaly); and (2) obtain linear slopes using the least-squares fitting method. The statistical significance of the linear trend was assessed with a statistical F-test [33].

\subsubsection{Calculation of Nonlinear Trend}

The nonlinear trends of Chl-a and Zsd were derived with ensemble empirical mode decomposition (EEMD), which is an adaptive signal decomposition algorithm for nonlinear 
time series widely used in many fields (e.g., [36,54-56]). A time series of Chl-a or Zsd can be decomposed with the EEMD method as follows:

$$
S(t)=\sum_{i=1}^{n} N_{i}(t)+R(t)
$$

where $N_{i}(t)$ and $R(t)$ represent the $i$-th intrinsic mode function (IMF) and the residual trend, respectively.

Here, the residual trend $R(t)$ is the overall adaptive trend over the whole data span and varies with time after the intrinsic variability of multi-decadal and shorter timescales is removed [38]. Thus, the residual trend after adaptively removing all the IMFs was applied to reveal the long-term evolution of the Chl-a and Zsd series. To facilitate region-to-region comparisons, the instantaneous relative changing rate $(I R)$ at a pixel is used to evaluate a nonlinear trend and is expressed in the following form:

$$
I R(t)=\frac{d f(R(t))}{R(t)} \times 100 \%
$$

where $d f$ denotes the temporal derivative.

\section{Results}

\subsection{Validation of the OC-CCI Products}

In the build-up of Chl-a match-ups, each in situ Chl-a measurement was matched with the nearest non-missing pixel within $0.6 \mathrm{~km}$ on the same day. A total of 13 match-ups were obtained (Figure 1). To demonstrate the consistency of the Chl-a in the satellite and in situ observations, the root mean square error (RMSE), mean absolute percentage error (MAPE) and correlation coefficient $(r)$ were calculated $[11,29,35,53]$ :

$$
\begin{gathered}
R M S E=\sqrt{\frac{\sum_{i=1}^{n}\left(\log _{10}\left(M_{i}\right)-\log _{10}\left(O_{i}\right)\right)^{2}}{n}} \\
M A P E=\frac{1}{n} \sum_{i=1}^{n} \frac{\left|M_{i}-O_{i}\right|}{O_{i}}
\end{gathered}
$$

where $M$ and $O$ represent the $\mathrm{Chl}$-a data from satellite and in situ observations, respectively, and $n$ is the total number of match-ups. Also note that the correlation coefficient $r$ was calculated based on the log10-transformed Chl-a. As shown in Figure 3, the OC-CCI Chl-a generally agreed well with in situ Chl-a, with $r, R M S E$ and MAPE values of 0.77, 0.19 and $35.62 \%$, respectively.

As for the OC-CCI Zsd, the mean absolute relative difference between the in situ and semi-analytical retrieved $Z s d$ was $18.2 \%$ [11,34]. In addition, Pitarch et al. [6] reported that the $Z s d$ derived from the OC-CCI $R_{r s}$ has an uncertainty of $\sim 32 \%$ when compared to the in situ Zsd.

Based on the aforementioned results, we can conclude that the accuracy of the OC-CCI Chl-a and Zsd was generally acceptable for application in remote sensing and DINEOF research. 


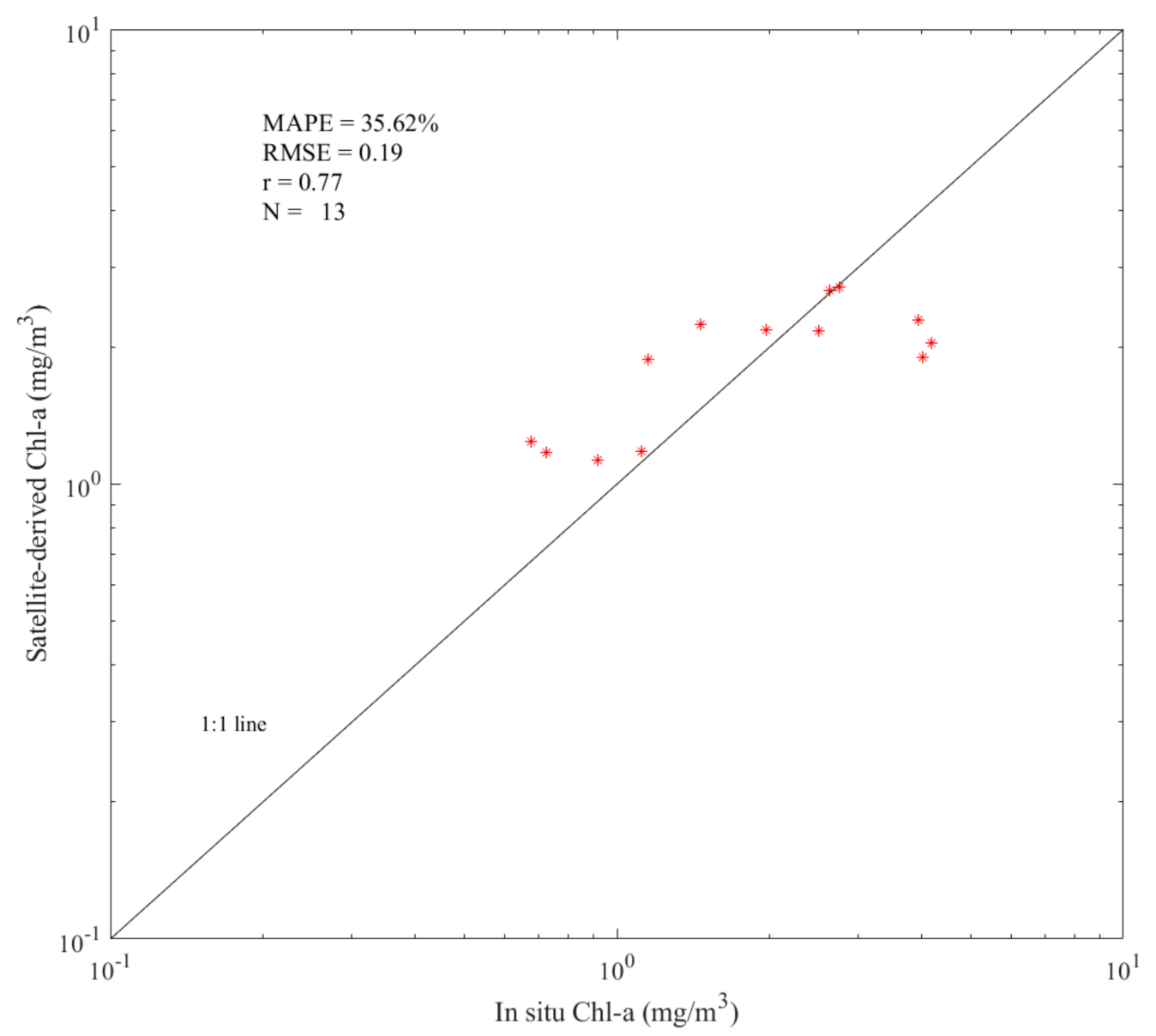

Figure 3. In situ Chl-a compared to the OC-CCI Chl-a.

\subsection{Validation of the Cloud-Free Chl-a and Zsd}

To evaluate the performance of the DINEOF method, $5 \%$ of the non-missing pixels in the OC-CCI products were randomly removed. These were treated as "missing pixels" for cross-validation purposes. The residual data were used to reconstruct pixels based on the DINEOF method. By calculating $r$, RMSE and MAPE between the artificially removed data and reconstructed data, the performance of the DINEOF method can be assessed. Note that for the Chl-a, the log10-transformed values were used.

Figure 4 shows a comparison of the DINEOF reconstructed data and the satellitemeasured data at the cross-validation points (the artificially removed data). Most points were close to the 1:1 line for both Chl-a and Zsd. For the Chl-a $(Z s d)$, MAPE $=13.75 \%$ $(16.37 \%)$, RMSE $=0.08(0.51)$ and $r=0.96$ (0.98). In addition, the means of the reconstructed/ satellite-measured ratios were $99.06 \%$ for Chl-a and $99.93 \%$ for $\mathrm{Zsd}$. There results verified the reliability and accuracy of the DINEOF method. Therefore, the monthly cloud-free satellite data reconstructions based on the DINEOF method can be used to study the spatio-temporal variations of water quality in the Bohai Sea. 

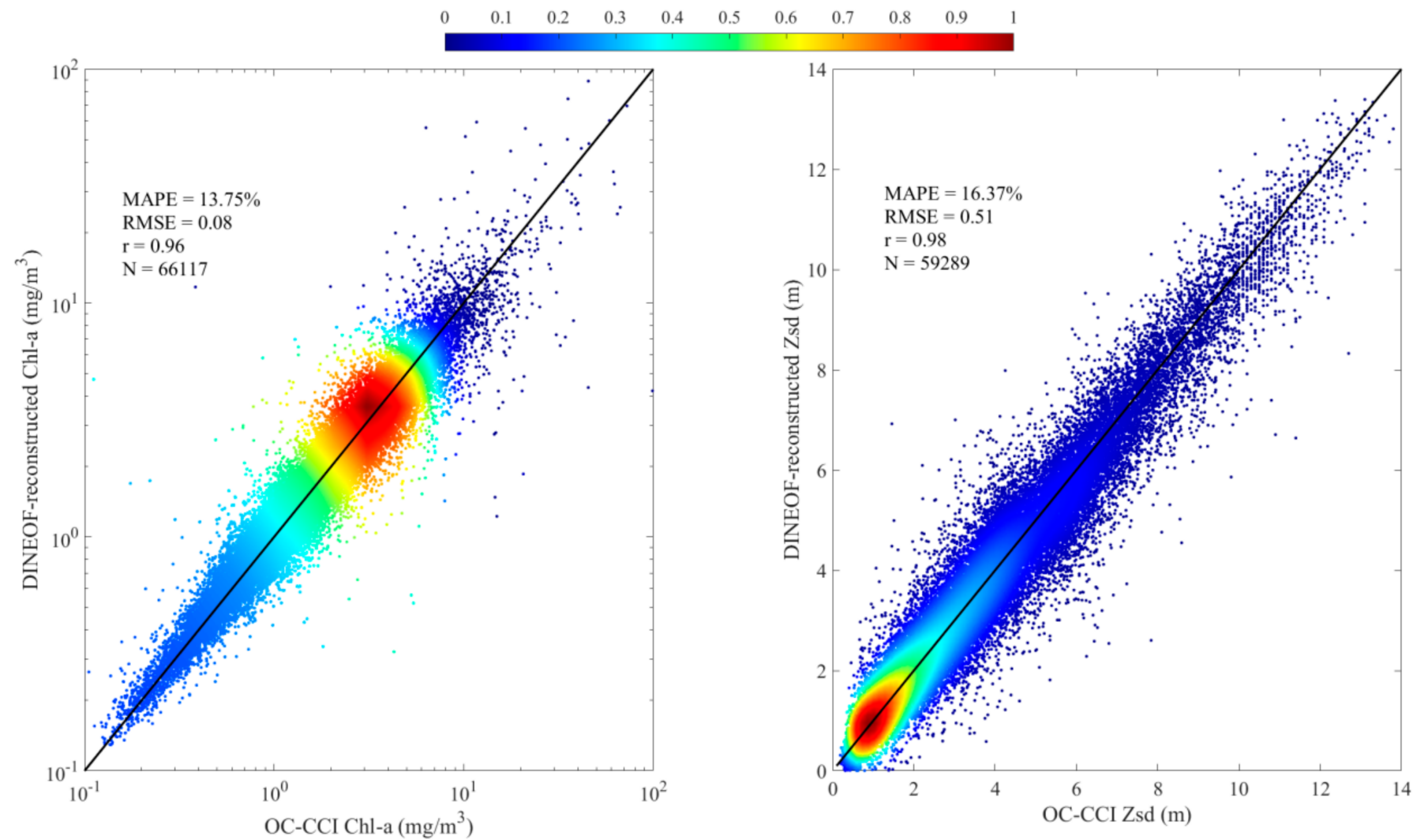

Figure 4. Scatterplots of satellite-measured versus the DINEOF reconstructed Chl-a (left) and Zsd (right). The coded color represents the relative density.

\section{Discussion}

\subsection{Relationship among the Reconstructed Chl-a and Zsd}

Based on the cloud-free reconstructions, Figure 5 shows the correlation map of the $\log 10$ (Chl-a) and Zsd time series. Only the correlation coefficient, which is significant at the $95 \%$ confidence level, is shown. Except for some pixels in Bohai Bay and Laizhou Bay, the Zsd shows significant negative correlation with the $\log 10$ (Chl-a). According to the demarcation line in Figure 1, the averaged $r$ scores were $-0.51,-0.67,-0.71$ and -0.83 in the Bohai Bay, Laizhou Bay, Liaodong Bay and central Bohai Sea, respectively. Due to human activities, coastal currents and the river outflow, the correlation coefficient between $\log 10(\mathrm{Chl}-\mathrm{a})$ and $\mathrm{Zsd}$ in the coastal waters displayed weaker patterns. In addition, the correlation coefficient was lower than -0.8 in most of the offshore waters.

Our results confirmed the work of Morel et al. [57], in which the cubic polynomial was applied to offshore water areas (water depth is greater than $20 \mathrm{~m}$ ) and the corresponding best fit was expressed as (black curve in Figure 6):

$$
Z_{s d}=1.26 X^{3}+4.24 X^{2}-8.78 X+3.79\left(R^{2}=0.88, R M S E=0.93\right)
$$

where $X=\log 10(\mathrm{Chl}-\mathrm{a})$. It can be seen from Figure 6 that good fitting relationships are found when the Chl-a levels are low $\left(<10 \mathrm{mg} / \mathrm{m}^{3}\right)$, which indicates that the Chl-a concentration could be an intermediate tool to estimate the $\mathrm{Zsd}$ for the offshore waters in the Bohai Sea. However, apparent biases from the fitting relationship are found when the Chl-a levels are moderate or high $\left(>15 \mathrm{mg} / \mathrm{m}^{3}\right)$. 


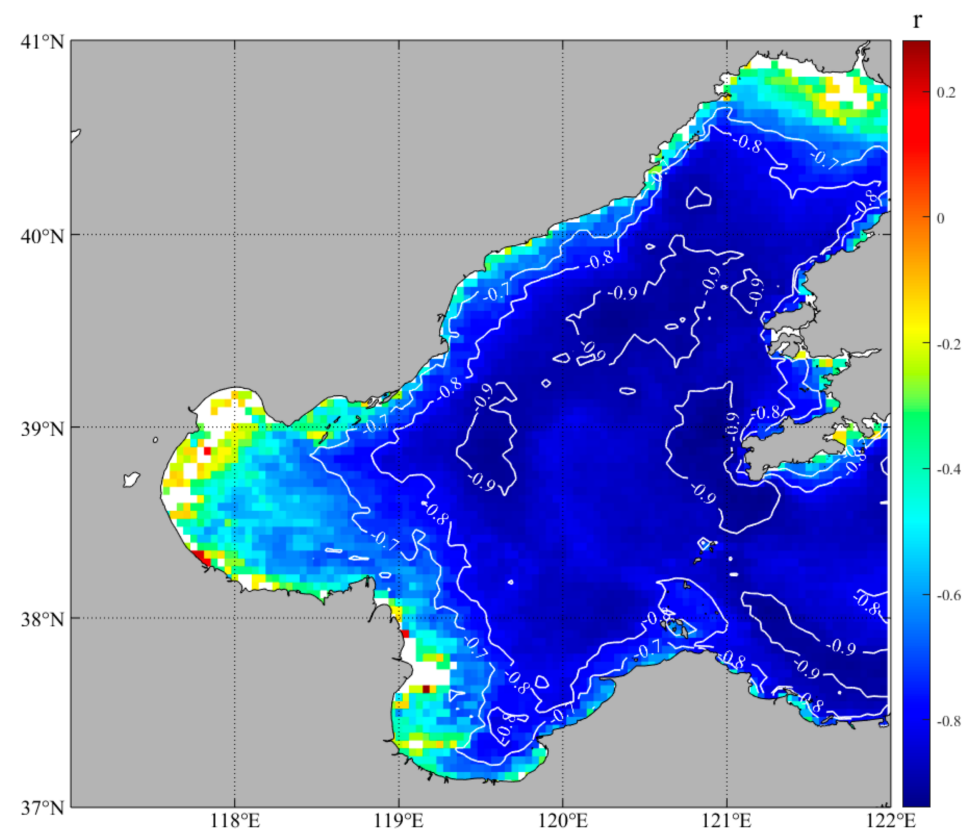

Figure 5. Correlation coefficient between $\log 10$ (Chl-a) and Zsd time series. The white lines represent contours of -0.9 to -0.7 .

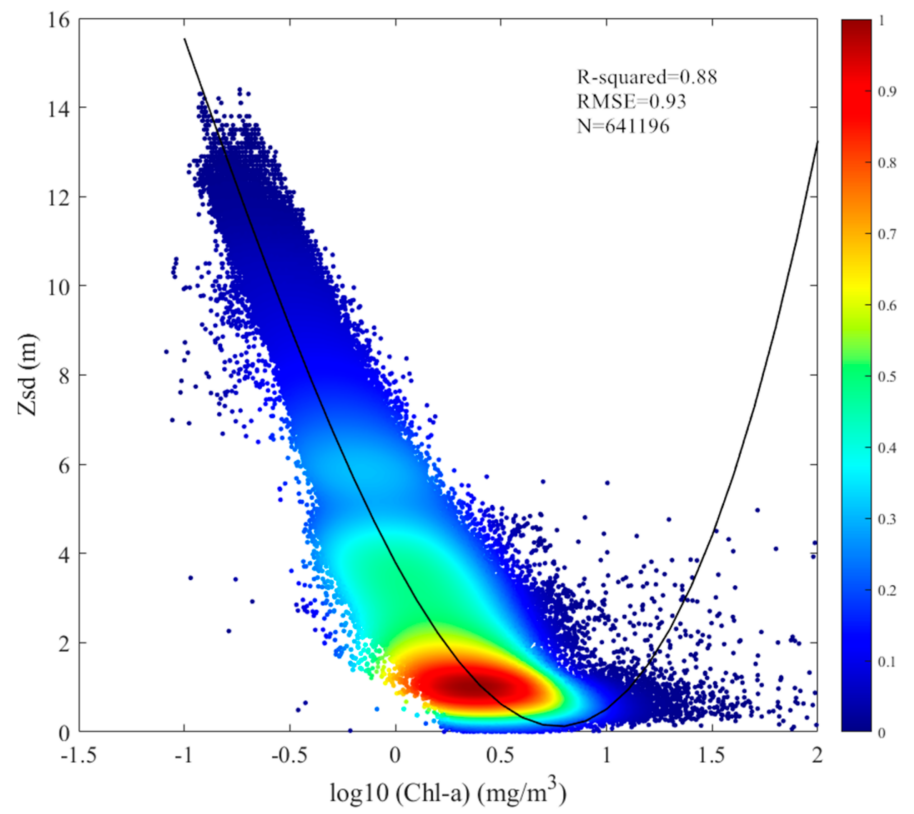

Figure 6. Scatter relationship between $\log 10$ (Chl-a) and Zsd. The coded colors and black lines represent the relative density and fit line, respectively.

\subsection{Spatio-Temporal Patterns of Chl-a and Zsd in the Bohai Sea}

The climatological mean maps of Chl-a and Zsd of 1997-2019 in the Bohai Sea were produced by averaging each pixel of the respective reconstructed maps. As shown in Figure 7, the climatological mean Chl-a concentrations decreased from the coastal waters to offshore waters, while Zsd generally exhibits an opposite pattern to that of Chl-a. These phenomena agree with previous studies (e.g., $[14,33,35,37])$. 

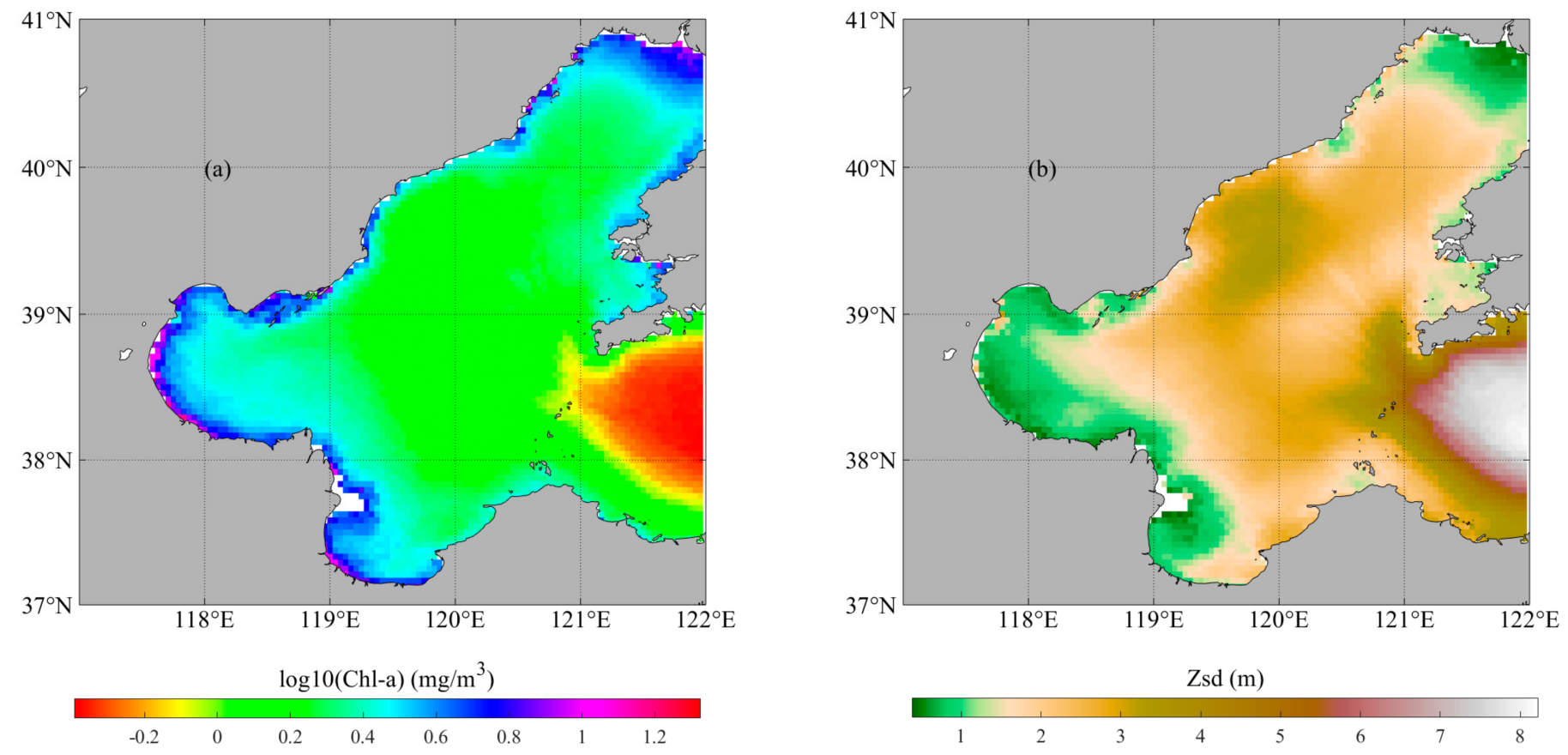

Figure 7. Climatological mean images of Chl-a (a) and Zsd (b) in the Bohai Sea, 1997-2019.

At every pixel, the standard deviation (SD) and coefficient of variation (CV) of Chla and Zsd were calculated. The SD and CV were mainly dominated by the seasonal variability of the cloud-free reconstructions, especially for the CV. Figure 8a shows a similar spatial pattern to Figure 7a. The highest SDs occurred near the boundary of Bohai Bay and Liaodong Bay $\left(>10 \mathrm{mg} / \mathrm{m}^{3}\right)$, while the lowest SDs appeared in the Bohai Strait $\left(<0.6 \mathrm{mg} / \mathrm{m}^{3}\right)$. As shown in Figure 8 b, the highest CV of Chl-a was found along the Qinhuangdao coast $(>100 \%)$, which showed the most significant seasonality in the Bohai Sea. The possible cause for this phenomenon was the algal blooms started in the Qinhuangdao coastal waters in summer [3]. Additionally, the low CV of Chl-a mainly existed in the three bays of the Bohai Sea, which was attributed to the relatively high values of Chl-a in the three bays throughout the year. As for Zsd, the SD map generally exhibits an increased pattern seaward (Figure 8c). The highest SDs $(\sim 2.5 \mathrm{~m})$ were observed near the Bohai Strait, whereas the SDs in the Bohai Bay were almost all less than $1.5 \mathrm{~m}$. There was an area in the central of the Bohai Sea with SDs lower than surrounding areas, which may have been due to the lower values of $Z s d$ in this region (Figure $7 b$ ). In addition, it can be seen from Figure $8 \mathrm{~d}$ that the CVs of Zsd in the central Bohai Sea were much larger than that in the nearby Yellow Sea, which indicated that the seasonal variations of water transparency in the Bohai Sea were more significant.

\subsection{Linear Trends in Chl-a and Zsd}

The spatial patterns of linear trends for Chl-a and Zsd over the period 1997-2019 are presented in Figure 9. Figure 9a shows that negative Chl-a trends are found in most of the Bohai Sea (73.86\% of the area) and positive Chl-a trends only occupy $26.14 \%$. Furthermore, only $47.30 \%$ of the area showed significant linear slopes (Figure 9c), in which significant positive and negative slopes occupied $5.21 \%$ and $42.09 \%$ of the basin, respectively. The significant negative Chl-a slopes mainly occurred in the three bays of the Bohai Sea, while only some small patches near the coastline present significant positive slopes of Chl-a. Additionally, the trends along the coastline are doubtful due to high levels of suspended sediment, which can lead to the large uncertainties of the OC-CCI Chl-a [58]. In the large area of the central Bohai Sea, the Chl-a exhibited non-significant long-term trends. The linear trends of Zsd generally show a pattern opposite to that of Chl-a, except for the central Bohai Sea (Figure 9b,d). Zsd over most of the three bays presented with a significant 
increasing trend, which indicates improved water quality in the coastal waters of the Bohai Sea. However, $\mathrm{Zsd}$ in the central Bohai Sea (center coordinate $120^{\circ} \mathrm{E}, 39^{\circ} \mathrm{N}$ ) was mainly dominated by the negative trends. Overall, significant positive and negative Zsd trends occurred at $40.86 \%$ and $19.15 \%$ rates, respectively.
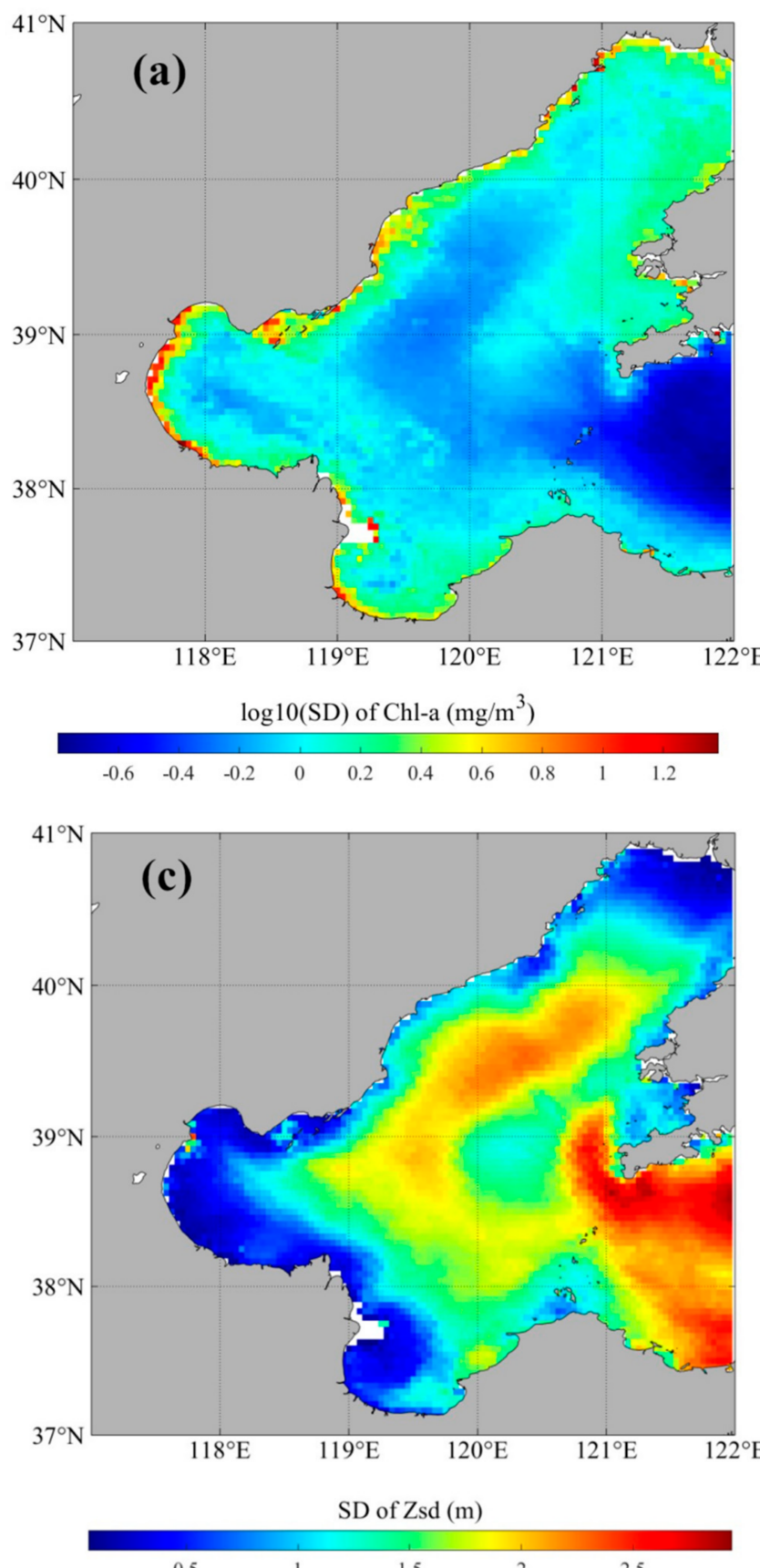
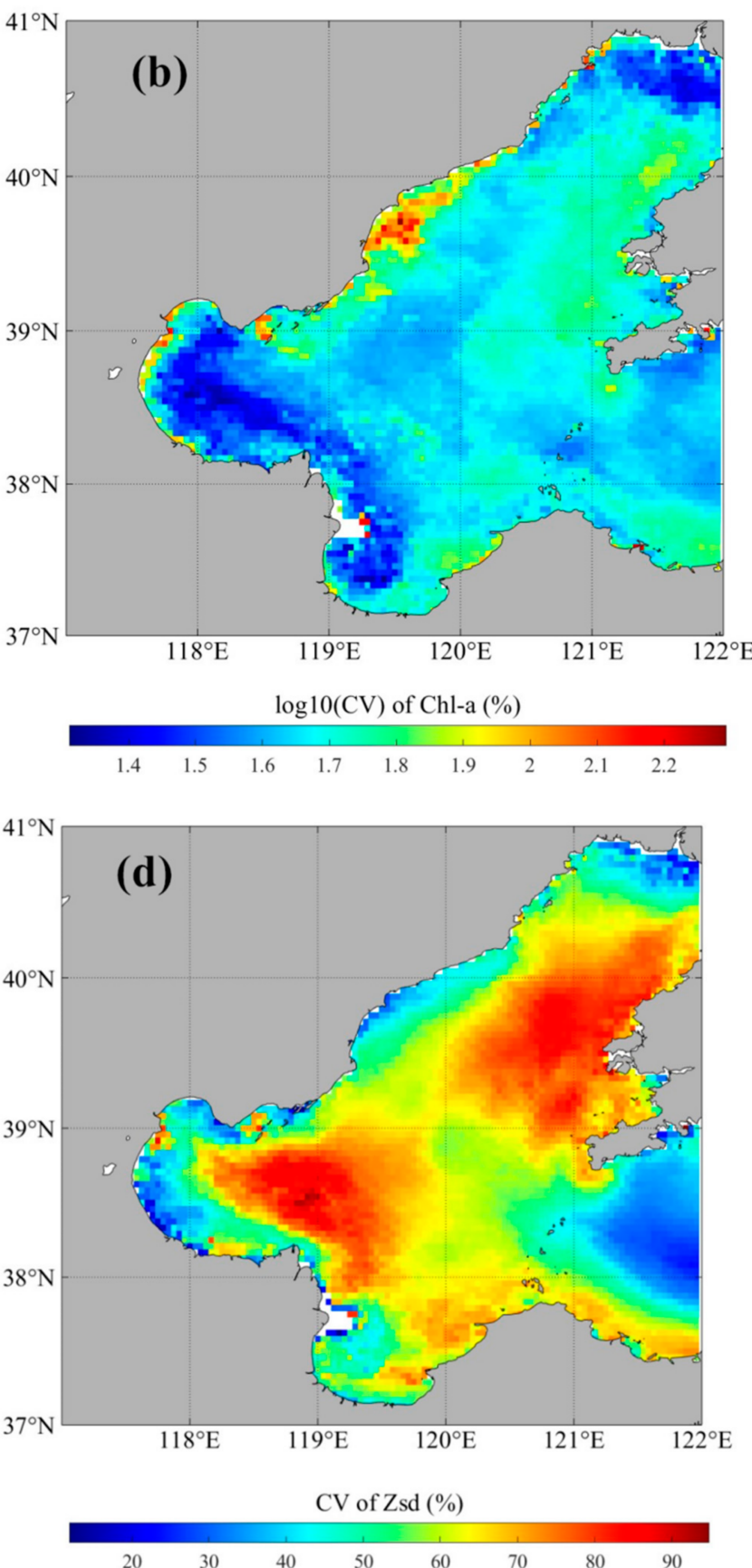

Figure 8. SD maps of (a) Chl-a and (c) Zsd during 1997-2019. CV maps of (b) Chl-a and (d) Zsd during 1997-2019. 

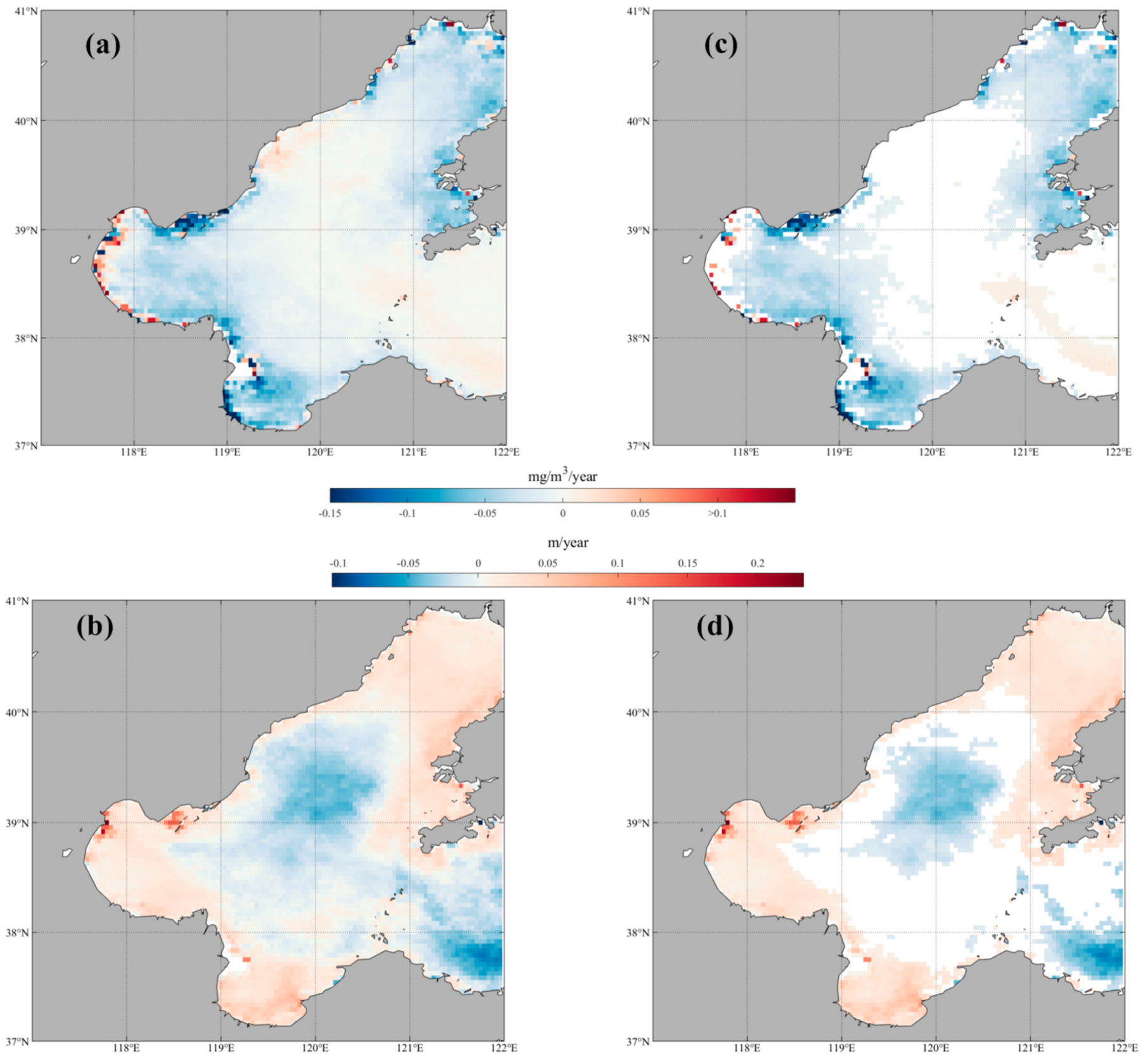

Figure 9. Linear trends of (a) Chl-a and (b) Zsd anomaly for the Bohai Sea over the period 1997-2019. Significance in F-test for (c) Chl-a and (d) Zsd anomaly: $p<0.05$.

The linear trends of the regionally averaged Chl-a and Zsd anomaly in the entire Bohai Sea, its three bays and its central region are shown in Figure 10. The Chl-a showed a significant decreasing trend from 1997-2019 in the five regions, with slopes of $-0.033 \mathrm{mg} / \mathrm{m}^{3} /$ year, $-0.026 \mathrm{mg} / \mathrm{m}^{3} /$ year, $-0.02 \mathrm{mg} / \mathrm{m}^{3} /$ year, $-0.0066 \mathrm{mg} / \mathrm{m}^{3} /$ year and $-0.013 \mathrm{mg} / \mathrm{m}^{3} /$ year in Bohai Bay, Laizhou Bay, Liaodong Bay, the central sea and the entire Bohai Sea (Figure 10a-e), respectively. On the other hand, the Zsd had a significant increasing trend except for the central Bohai Sea (Figure 10f-j). The increasing rates in Bohai Bay, Laizhou Bay, Liaodong Bay and the entire Bohai Sea were $0.021 \mathrm{~m} /$ year, $0.014 \mathrm{~m} /$ year, $0.021 \mathrm{~m} /$ year and $0.0065 \mathrm{~m} /$ year, respectively. No significant trend was found in the central Bohai Sea, suggesting that the water transparency remained largely the same during 1997-2019. Shang et al. [11] reported a similar result in the central Bohai Sea during 2003-2014. 

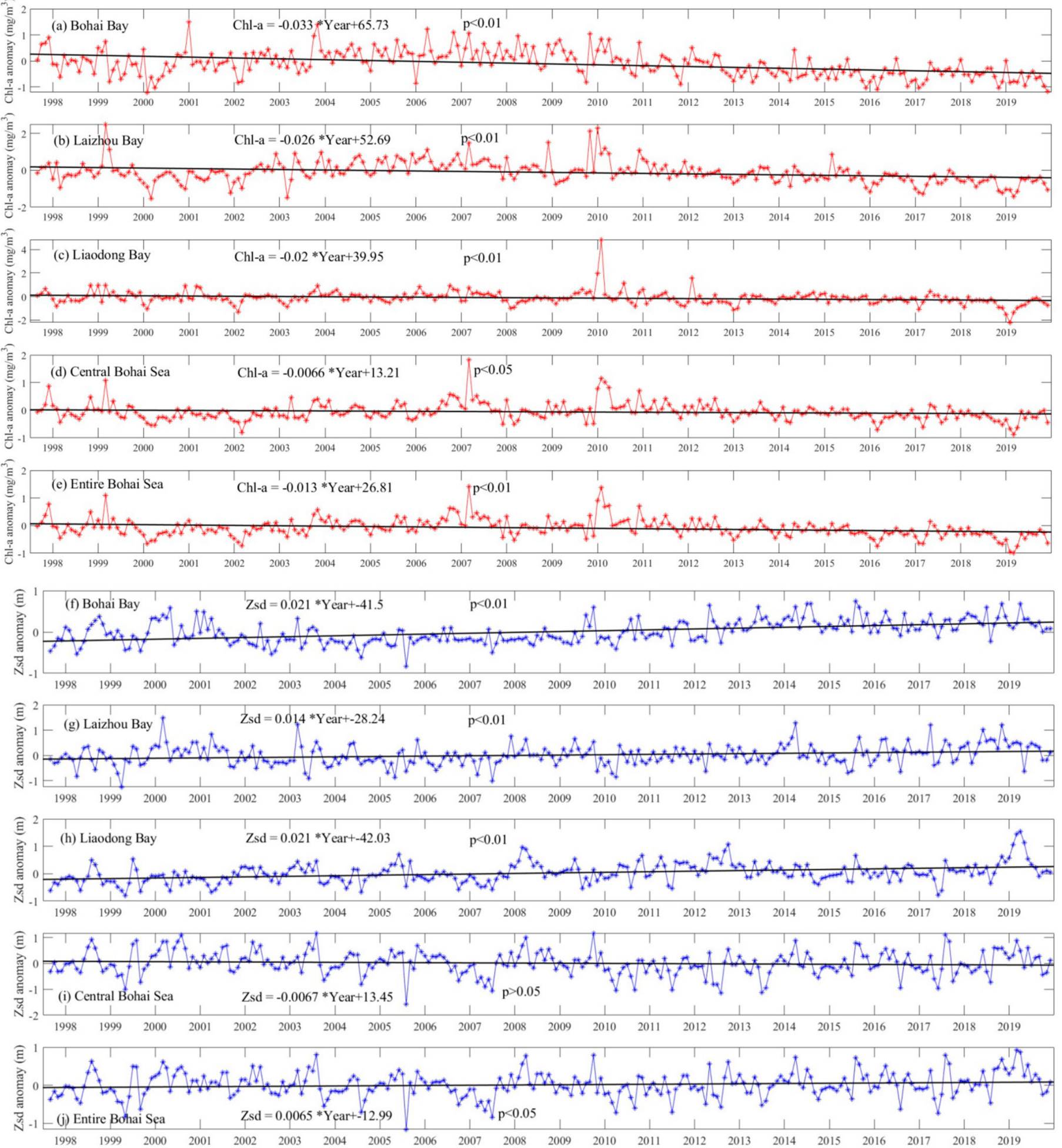

Figure 10. Line trends of the Chl-a anomaly for (a) Bohai Bay, (b) Laizhou Bay, (c) Liaodong Bay, (d) the central Bohai Sea and (e) the entire Bohai Sea. (f-j) Same as in (a-e) but for Zsd.

The linear trends of Chl-a and Zsd anomalies in different seasons are summarized in Figure 11. Overall, the inter-annual variations of two optical variables occurred in all four seasons. The most evident feature is that the Chl-a decreases significantly and Zsd increases significantly throughout the year for the Bohai Bay. This result indicates that the increase of water transparency in the Bohai Bay from 1997 to 2019 might be caused by the decrease of Chl-a. At the temporal scale, the Chl-a and Zsd trends showed significant values in autumn, 
expect for the Zsd trend in the central Bohai Sea. The areas with significant linear seasonal trends, such as the trend of $Z s d$ anomaly in the central Bohai Sea being dominant during summer $(-0.036 \mathrm{~m} /$ year $)$, were also identified.
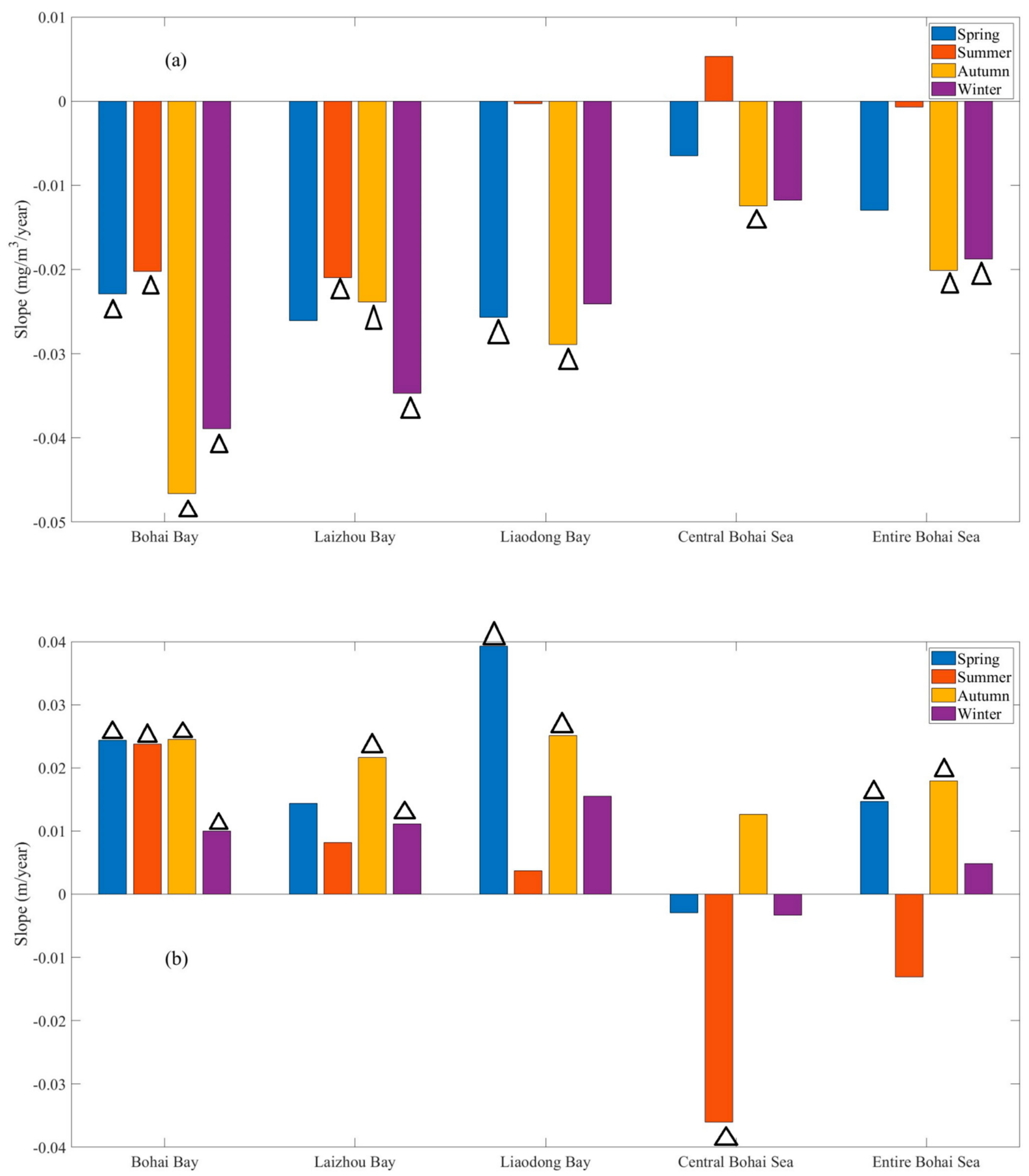

Figure 11. Linear trends of Chl-a (a) and Zsd (b) seasonal anomalies for the different regions (triangle mark represents significant linear trend). 


\subsection{Nonlinear Trends in Chl-a and Zsd}

The nonlinear trends of Chl-a and Zsd when analyzed using the EEMD method are interpreted in Figures 12 and 13, respectively. Figure 12 shows the averaged IR (Equation (3)) in 1998-2019 (the incomplete year of 1997 was not shown), from which the spatio-temporal evolution of Chl-a was detected. The positive and negative IRs represent increasing and decreasing trends, respectively. The Chl-a exhibited apparent temporal variability over the whole Bohai Sea, with weakened positive IRs from 1998 to 2003, and enhanced negative IRs from 2007 to 2019. In addition, there are some sporadic pixels in the central Bohai Sea that show persistently positive IRs of Chl-a over the study period. As for the Zsd (Figure 13), the strong positive trend in the Liaodong Bay and central Bohai Sea has been gradually weakened since 1998, while the positive trend in Bohai Bay and Laizhou Bay has been enhanced since 2003. As a comparison, the spatial distribution of the IRs in specific years (Figures 12 and 13) were quite different from the linear regression maps during 1997-2019 (Figure 9). Therefore, the linear slopes may not clearly show the long-term change to the Chl-a and Zsd series.
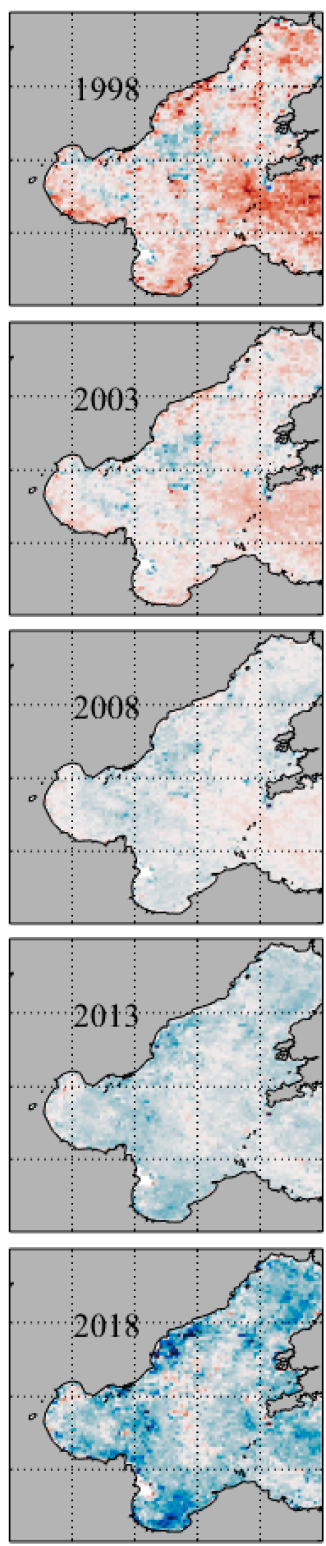
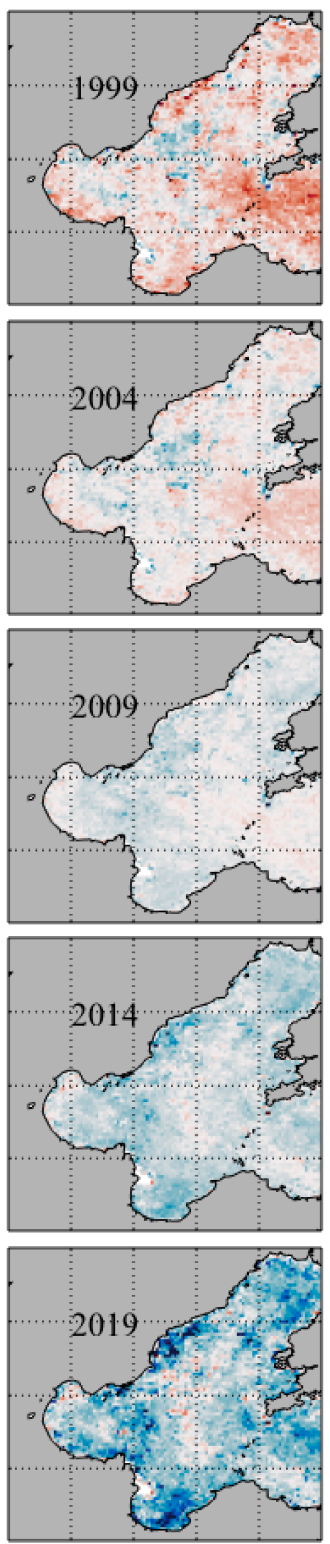
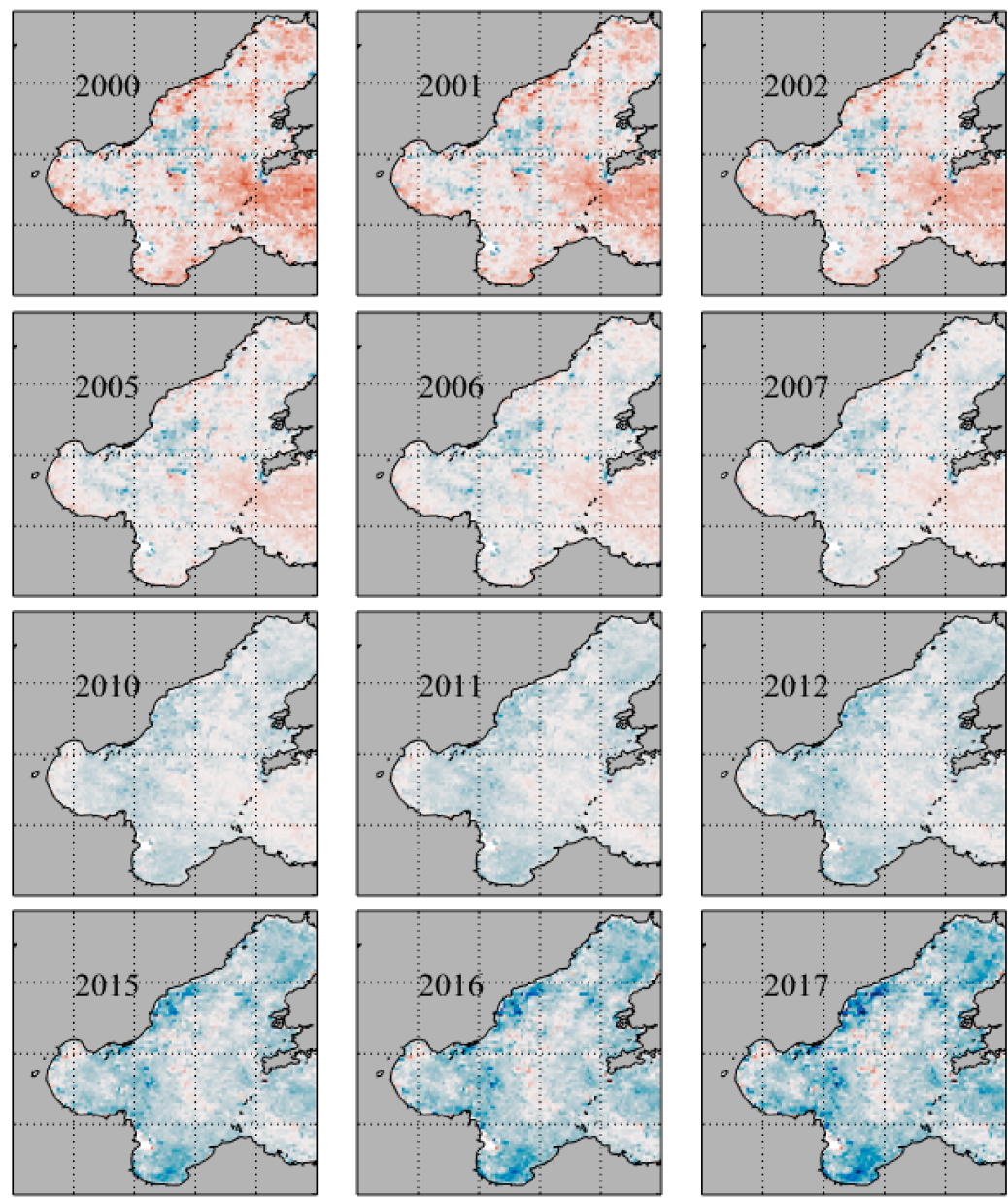

$(\% /$ year $)$

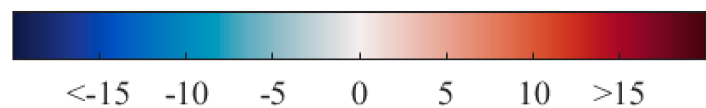

Figure 12. Spatio-temporal patterns of the Chl-a IRs, 1998-2019. 

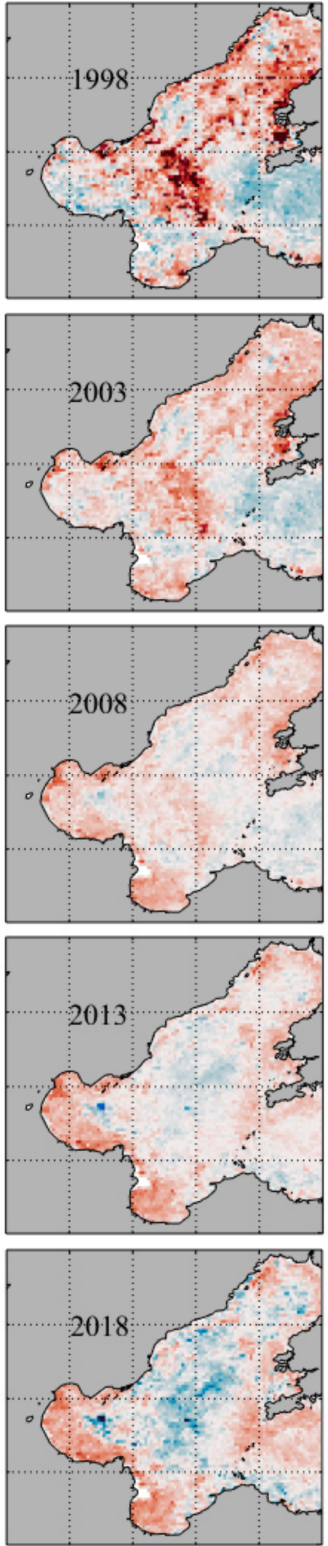
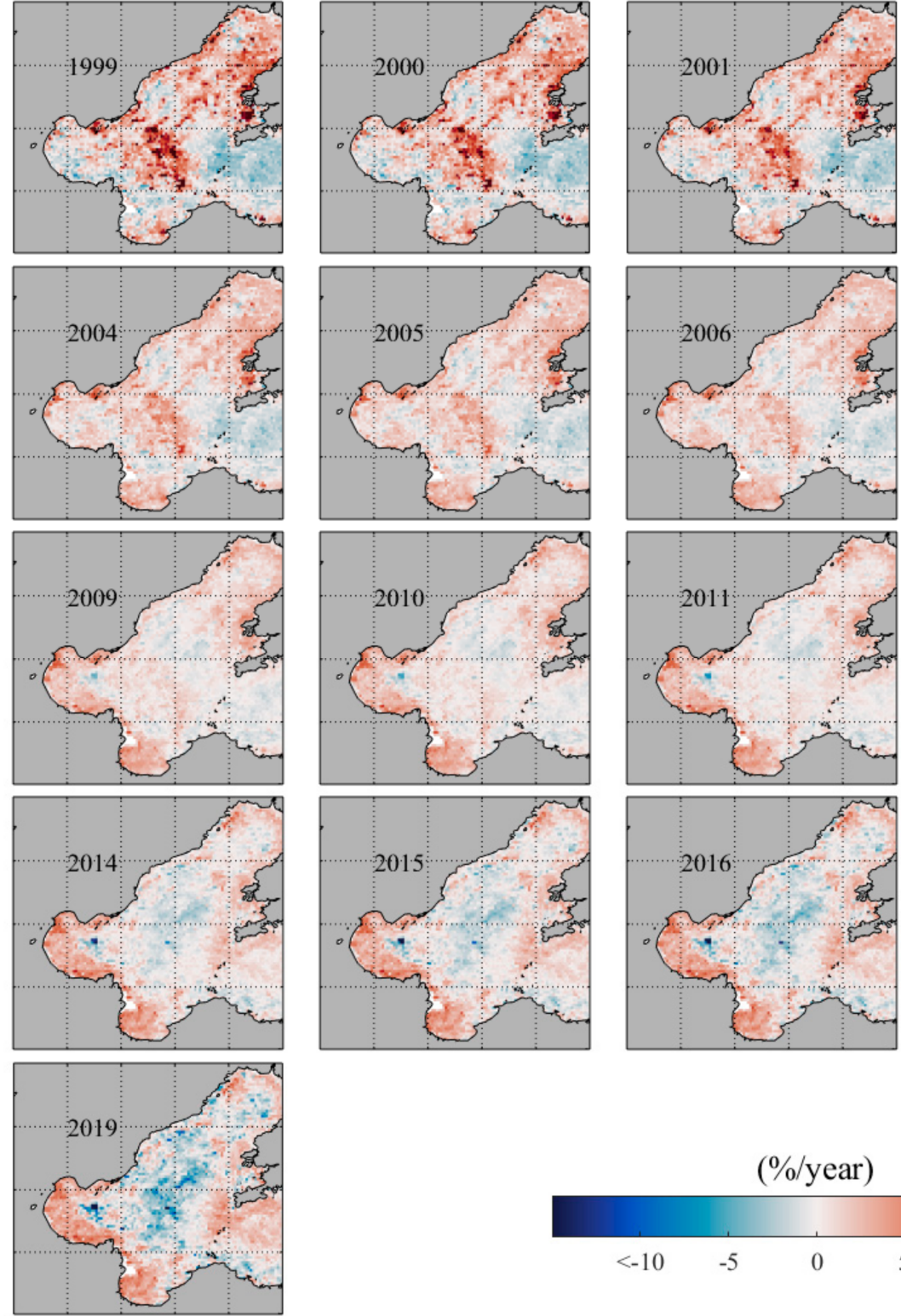
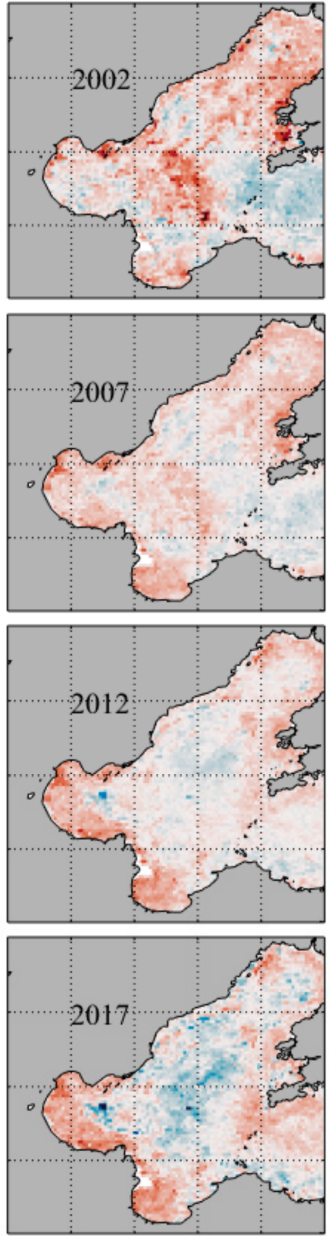

$(\% /$ year $)$

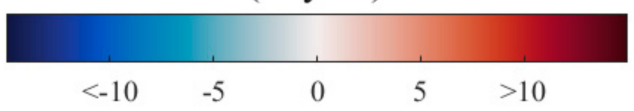

Figure 13. Same as in Figure 12 but for Zsd.

The regionally averaged IRs of Chl-a and Zsd in the Bohai Bay, Laizhou Bay, Liaodong Bay, central Bohai Sea and entire Bohai Sea are shown in Figure 14. The nonlinear trends are apparent in all the five regions for both Chl-a and Zsd. The Chl-a in these regions first shows an increasing trend from 1998 and then a decreasing trend from around 2005 (Figure 14a). The regionally averaged IRs of the Chl-a series for the entire Bohai Sea almost continuously decreased from $\sim 2 \%$ /year in 1998 to about $-4 \%$ /year in 2019. Additionally, the turning points between the positive and negative trends were different in different regions (between 2003 and 2006). The regionally averaged IRs of Zsd (Figure 14b) generally exhibited an increasing trend in Zsd throughout the study period, except for the central Bohai Sea, in the later stage. The highest IR of Zsd was observed in the Liaodong Bay, at a rate of $\sim 4 \%$ /year. Overall, the IRs of Zsd over the entire Bohai Sea were continuously reduced from 1997 to 2019 from $\sim 2.8 \%$ /year to $\sim 1 \% /$ year. 

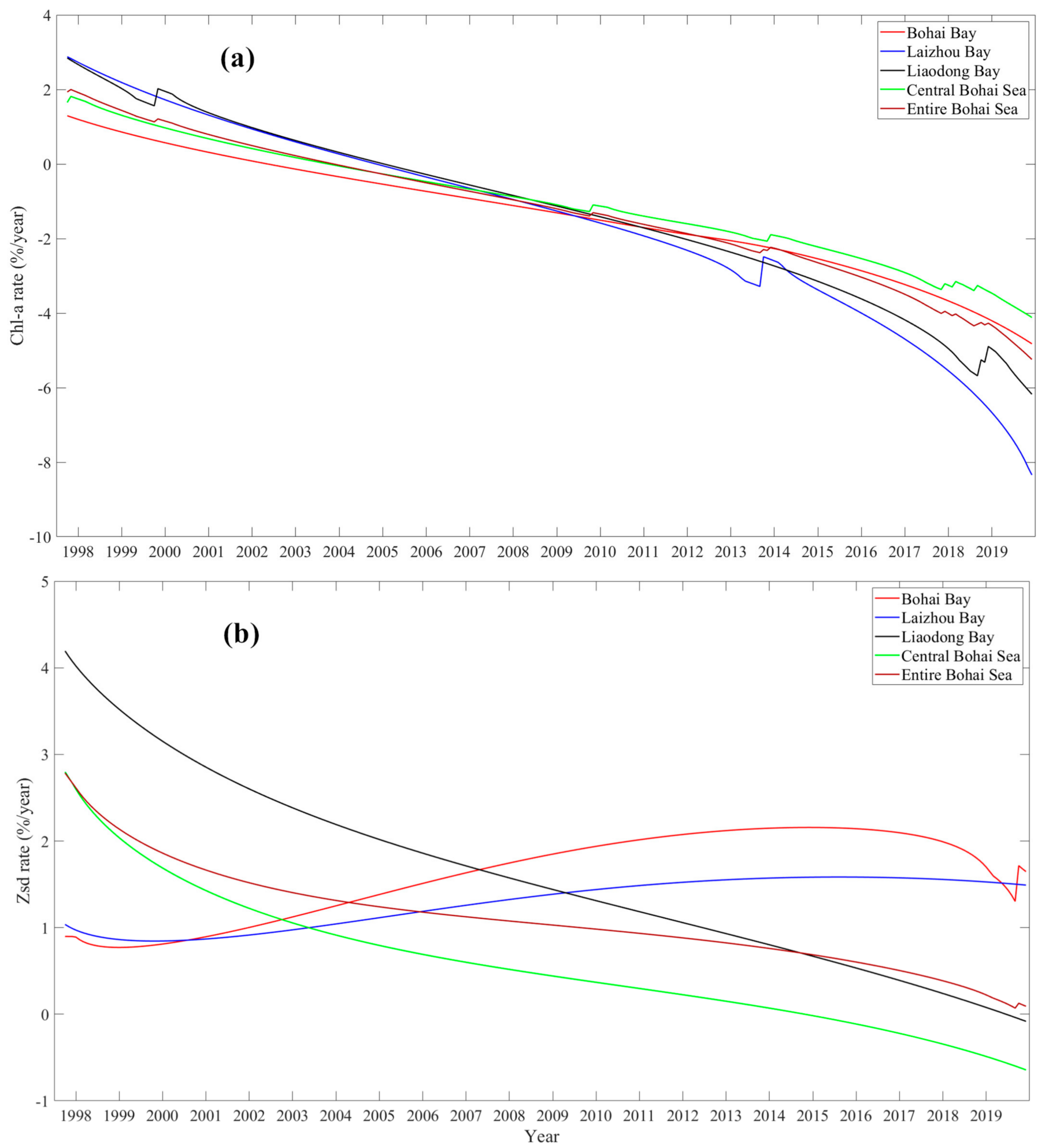

Figure 14. The instantaneous relative changing rates (IRs) of Chl-a (a) and Zsd (b) for the five different regions.

\subsection{Factors Affecting Water Quality and Application of the Cloud-Free Reconstruction}

It is generally accepted that the water quality of the Bohai Sea was rapidly degraded in the last century [59]. However, the linear and nonlinear maps of Chl-a and Zsd indicate the deterioration of water quality was not continued over the past two decades, which may be due to the stability of large-scale wind patterns and lessening of human disturbances (control of sewage and river dams) [14]. The discharge of wastewater is an important 
factor for the deterioration of water quality. Since the Bohai Sea ecosystem had been rapidly degraded, the Chinese government initiated a series of measures to protect the Bohai Sea in 2001. Many measures include laws and regulations that wastewater must be treated and controlled, and that more environmentally friendly industries need to be developed [14]. These measures might have reduced the discharge of substantial landsourced nutrients, which may contribute to the improvement of water quality in the Bohai Sea. Apart from human disturbances, wind field is also an important factor contributing to the variations of Chl-a and $\mathrm{Zsd}$ through the seasonal and interannual variability of wind mixing [3,35]. The Bohai Sea is under the influence of monsoons and the circulation field, thusly exhibiting significant seasonal variation [37,60]. Wave rose and wind rose diagrams and current patterns for different seasons may be included to support the Secchi disk depth variations for the negative Chlorophyll variations. Moreover, the decrease of SST would result in stronger vertical mixing, which would provide nutrients for the growth of phytoplankton and help suspended particles enter the water column more easily $[3,33,34]$. However, the evolution of Chl-a and Zsd are complicated and could not be fully explained by several factors. This complicated phase change might be caused by many physical and environmental factors, including ocean heat content, current patterns, degree of the turbulence, wind field, SST, river outflow, or global climate changes, but this determination is outside the scope of this study. A forthcoming study is planned to explore the potential natural and anthropogenic drivers related to the linear and nonlinear trends of the cloud-free Chl-a and Zsd in the Bohai Sea.

The DINEOF reconstructed images provide a unique way to investigate low-frequency changes to the water quality of the Bohai Sea. In addition, eutrophication is a serious water quality challenge. Due to the complex optical properties of the Bohai Sea, the Trophic Level Index from multiple variables is limited in its usefulness [61]. Satellite-derived Chl-a and $Z s d$ can be used as a proxy for the trophic state index (TSI) for water trophic state assessment in environmental communication $\left(\operatorname{TSI}(\mathrm{Chl}-a)=10\left[6-\frac{2.04-0.68 \ln (\mathrm{Chl}-a)}{\ln 2}\right], \operatorname{TSI}\left(\mathrm{Z}_{s d}\right)=\right.$ $\left.\left.10\left[6-\frac{\ln \left(Z_{s d}\right)}{\ln 2}\right]\right)\right)$ [62]. The TSI proposed by Carlson [62] divides the water trophic state into three classes: oligotrophic (TSI $(\mathrm{Chl}-\mathrm{a} / \mathrm{Zsd})<30)$, mesotrophic $(30 \leq \mathrm{TSI}(\mathrm{Chl}-\mathrm{a} / \mathrm{Zs} d)$ $<50)$, and eutrophic (TSI $(\mathrm{Chl}-\mathrm{a} / \mathrm{Zs} d) \geq 50)$. The TSI $(\mathrm{Chl}-\mathrm{a} / \mathrm{Zs} d)$ is simple and easy to use, so the TSI method with the cloud-free data can be an effective tool in marinemanagement programs.

Although the DINEOF method employed herein was applied for a regional study, it is also applicable on a global scale. Monthly cloud-free Chl-a and Zsd series can help to show the response of aquatic ecosystems to physical and environmental changes. Furthermore, research on the DINEOF method could also provide a potential reference for the interpolation of other water color variables, such as Forel-Ule, $K d(490)$, total suspend matter, turbidity and chromophoric dissolved organic matter.

\section{Conclusions}

In this study, the monthly Chl-a and Zsd data of the Bohai Sea were produced with the ESA-OC-CCI data from $1997-2019$, defined by the location $37^{\circ}-41^{\circ} \mathrm{N}$ and $117^{\circ}-122^{\circ} \mathrm{E}$. The DINEOF method was used to reconstruct the missing data caused by the cloud cover, high sun-glint contamination and other reasons. The results of the cross-validation show the accuracy of cloud-free reconstructions based on the DINEOF method. Based on the 23-yeara cloud-free reconstruction s, significant negative correlation relationship among the $\log 10$ (Chl-a) and Zsd series was identified in the Bohai Sea. In addition, it was found that the $\mathrm{Zsd}$ as a function of $\log 10$ (Chl-a) can be well fitted by the cubic polynomial $Z_{s d}=1.26 X^{3}+4.24 X^{2}-8.78 X+3.79\left(R^{2}=0.88, R M S E=0.93\right)$ in the offshore waters.

In the past $\sim 23$ years, a linear regression generally shows a decreasing Chl-a trend $\left(-0.013 \mathrm{mg} / \mathrm{m}^{3} /\right.$ year, $\left.p<0.01\right)$ and an increasing Zsd trend $(0.0065 \mathrm{~m} /$ year, $p<0.05)$ for the entire Bohai Sea, with significant regional-seasonal differences (Figure 11). Moreover, the inter-annual patterns of Bohai Bay (Chl-a, $-0.033 \mathrm{mg} / \mathrm{m}^{3} /$ year; $Z s d, 0.021 \mathrm{~m} /$ year), Laizhou Bay (Chl-a, $-0.026 \mathrm{mg} / \mathrm{m}^{3} /$ year; Zsd, $0.014 \mathrm{~m} /$ year) and Liaodong Bay (Chl-a, 
$-0.02 \mathrm{mg} / \mathrm{m}^{3} /$ year; Zsd, $0.021 \mathrm{~m} /$ year) were investigated $(p<0.01)$. The EEMD analysis of the Chl-a and Zsd series demonstrates strong nonlinear trends and time-varying IRs over the Bohai Sea. Based on the linear and nonlinear analysis of two optical variables, we can infer improvements to the water quality in the three bays of the Bohai Sea, which may be attributed to sound management of the quality of aquatic ecosystems in the Bohai Sea.

The results of this work demonstrate the value of both the remote sensing and DINEOF methods in assessing water quality based on long-term observations. This study also proves the necessity of investigating Chl-a and Zsd simultaneously, due to their high negative correlation.

Author Contributions: Conceptualization, S.Z. and D.W.; formal analysis, S.Z. and D.W.; project administration, Y.Z., S.Z. and X.L.; funding acquisition, Y.Z., S.Z. and X.L.; investigation, J.G.; methodology, J.G. and C.Z.; software, J.G.; validation, J.G., J.L., C.Z. and S.Z.; supervision, J.L., Y.Z., S.Z. and D.W.; writing—original draft, J.G.; writing—review and editing, J.G., J.L., Y.Z., C.Z., S.Z., D.W. and X.L. All authors have read and agreed to the published version of the manuscript.

Funding: This work was supported by the National Key Research and Development Program of China (Grant No. 2018YFC1407602) and the National Natural Science Foundation of China (Grant Nos. 42076011, U1806214 and 42106033).

Data Availability Statement: Monthly OC-CCI $R_{r s}$ and Chl-a data used in our study can be downloaded from https:/ / esa-oceancolour-cci.org/ (accessed on 15 September 2021).

Acknowledgments: The authors are grateful to the ESA-OC-CCI project for providing satellitederived data. We would like to thank Anzhou Cao and Haidong Pan for their grammar review and technical guidance of this paper. Finally, we wish to thank the three anonymous reviewers for their valuable comments that helped the manuscript to be improved.

Conflicts of Interest: The authors declare no conflict of interest.

\section{References}

1. Huot, Y.; Babin, M. Does Chlorophyll a Provide the Best Index of Phytoplankton Biomass for Primary Productivity Studies? Biogeosciences Discuss. 2007, 4, 707-745.

2. Henson, S.A.; Sarmiento, J.L.; Dunne, J.P.; Bopp, L.; Lima, I.; Doney, S.C.; John, J.; Beaulieu, C. Detection of Anthropogenic Climate Change in Satellite Records of Ocean Chlorophyll and Productivity. Biogeosciences 2010, 7, 621-640. [CrossRef]

3. Fu, Y.; Xu, S.; Liu, J. Temporal-Spatial Variations and Developing Trends of Chlorophyll-a in the Bohai Sea, China. Estuar. Coast. Shelf Sci. 2016, 173, 49-56. [CrossRef]

4. Secchi, A. Relazione delle esperienze fatte a bordo della pontificia pirocorvetta Imacolata Concezione per determinare la trasparenza del mare; Memoria del P.A. Secchi. Il Nuovo Cim. G. Fis. Chim. Stor. Nat. 1865, 20, $205-238$.

5. Boyce, D.G.; Lewis, M.; Worm, B. Integrating Global Chlorophyll Data from 1890 to 2010. Limnol. Oceanogr. Methods 2012, 10, 840-852. [CrossRef]

6. Pitarch, J.; Marullo, S.; Van Der Woerd, H.J. Global maps of Forel-Ule index, hue angle and Secchi disk depth derived from 21 years of monthly ESA Ocean Colour Climate Change Initiative data. Earth Syst. Sci. Data. 2021, 13, 481-490. [CrossRef]

7. Moore, T.S.; Campbell, J.W.; Dowell, M.D. A class-based approach to characterizing and mapping the uncertainty of the MODIS ocean chlorophyll product. Remote Sens. Environ. 2009, 113, 2424-2430. [CrossRef]

8. Guo, J.; Nie, Y.; Sun, B.; Lv, X. Remote sensing of transparency in the China seas from the ESA-OC-CCI data. Estuar. Coast. Shelf Sci. 2022, 264, 107693. [CrossRef]

9. Moradi, M. Evaluation of merged multi-sensor ocean-color chlorophyll products in the Northern Persian Gulf. Cont. Shelf Res. 2021, 221, 104415. [CrossRef]

10. Lee, Z.; Shang, S.; Du, K.; Wei, J. Resolving the long-standing puzzles about the observed Secchi depth relationships. Limnol. Oceanogr. 2018, 63, 2321-2336. [CrossRef]

11. Lee, Z.; Shang, S.; Hu, C.; Du, K.; Weidemann, A.; Hou, W.; Lin, J.; Lin, G. Secchi Disk Depth: A New Theory and Mechanistic Model for Underwater Visibility. Remote Sens. Environ. 2015, 169, 139-149. [CrossRef]

12. Pitarch, J.; van der Woerd, H.J.; Brewin, R.J.W.; Zielinski, O. Optical properties of Forel-Ule water types deduced from 15 years of global satellite ocean color observations. Remote Sens. Environ. 2019, 231, 111249. [CrossRef]

13. Jackson, T.; Chuprin, A.; Sathyendranath, S.; Grant, M.; Zühlke, M.; Dingle, J.; Storm, T.; Boettcher, M.; Fomferra, N. Ocean Colour Climate Change Initiative (OC_CCI)-Interim Phase, Product User Guide, D3.4 PUG. Available online: https: / / esa-oceancolour-cci.org/sites/esa-oceancolour-cci.org/alfresco.php?file=a68aa514-3668-4935-9235-fca10f7e8bee\& name=OC-CCI-PUG-v4.1-v1.pdf (accessed on 29 December 2021). 
14. Shang, S.; Lee, Z.; Shi, L.; Lin, G.; Wei, G.; Li, X. Changes in Water Clarity of the Bohai Sea: Observations from MODIS. Remote Sens. Environ. 2016, 186, 22-31. [CrossRef]

15. Tang, Q.; Jin, X.; Wang, J.; Zhuang, Z.; Cui, Y.; Meng, T. Decadal-Scale Variations of Ecosystem Productivity and Control Mechanisms in the Bohai Sea. Fish. Oceanogr. 2003, 12, 223-233. [CrossRef]

16. Sündermann, J.; Feng, S. Analysis and Modelling of the Bohai Sea Ecosystem-A Joint German-Chinese Study. J. Mar. Syst. 2004, 44, 127-140. [CrossRef]

17. Zheng, Q.; Li, X.; Lv, X. Application of Dynamically Constrained Interpolation Methodology to the Surface Nitrogen Concentration in the Bohai Sea. Int. J. Environ. Res. Public Health 2019, 16, 2400. [CrossRef]

18. Ning, X.; Lin, C.; Su, J.; Liu, Q.; Hao, Q.; Le, F.; Tang, Q. Long-Term Environmental Changes and the Responses of the Ecosystems in the Bohai Sea during 1960-1996. Deep. Sea Res. Part II Top. Stud. Oceanogr. 2010, 57, 1079-1091. [CrossRef]

19. Liu, X.; Wang, M. Gap Filling of Missing Data for VIIRS Global Ocean Color Products Using the DINEOF Method. IEEE Trans Geosci. Remote Sens. 2018, 56, 4464-4476. [CrossRef]

20. Ma, C.; Zhao, J.; Ai, B.; Sun, S. Two-Decade Variability of Sea Surface Temperature and Chlorophyll-a in the Northern South China Sea as Revealed by Reconstructed Cloud-Free Satellite Data. IEEE Trans. Geosci. Remote Sens. 2021, 59, 9033-9046. [CrossRef]

21. Beckers, J.M.; Rixen, M. EOF Calculations and Data Filling from Incomplete Oceanographic Datasets. J. Atmos. Ocean. Technol. 2003, 20, 1839-1856. [CrossRef]

22. Alvera-Azcárate, A.; Barth, A.; Rixen, M.; Beckers, J.M. Reconstruction of Incomplete Oceanographic Data Sets Using Empirical Orthogonal Functions: Application to the Adriatic Sea Surface Temperature. Ocean Model. 2005, 9, 325-346. [CrossRef]

23. Alvera-Azcárate, A.; Barth, A.; Beckers, J.M.; Weisberg, R.H. Multivariate Reconstruction of Missing Data in Sea Surface Temperature, Chlorophyll, and Wind Satellite Fields. J. Geophys. Res. Ocean. 2007, 112, 1-11. [CrossRef]

24. Li, Y.; He, R. Spatial and Temporal Variability of SST and Ocean Color in the Gulf of Maine Based on Cloud-Free SST and Chlorophyll Reconstructions in 2003-2012. Remote Sens. Environ. 2014, 144, 98-108. [CrossRef]

25. Liu, X.; Wang, M. Filling the Gaps of Missing Data in the Merged VIIRS SNPP/NOAA-20 Ocean Color Product Using the DINEOF Method. Remote Sens. 2019, 11, 178. [CrossRef]

26. Liu, X.; Wang, M. Analysis of ocean diurnal variations from the Korean Geostationary Ocean Color Imager measurements using the DINEOF method. Estuar. Coast. Shelf Sci. 2016, 180, 230-241. [CrossRef]

27. Carter, E.F.; Robinson, A.R. Analysis models for the estimation of oceanic fields. J. Atmos. Ocean. Technol. 1987, 4, 49-74. [CrossRef]

28. Franke, R. Scattered Data Interpolation: Tests of Some Method. Math. Comput. 1982, 38, 181-200. [CrossRef]

29. Nie, Y.; Guo, J.; Sun, B.; Lv, X. An Evaluation of Apparent Color of Seawater Based on the In-Situ and Satellite-Derived Forel-Ule Color Scale. Estuar. Coast. Shelf Sci. 2020, 246, 107032. [CrossRef]

30. Guo, J.; Nie, Y.; Li, S.; Lv, X. Application of Three-Dimensional Interpolation in Estimating Diapycnal Diffusivity in the South China Sea. J. Mar. Sci. Eng. 2020, 8, 832. [CrossRef]

31. He, X.; Pan, D.; Huang, E.; Zhao, Y. Monitor of water transparency in the China Sea by using satellite remote sensing. Eng. Sci. 2004, 9, 33-37. [CrossRef]

32. Cui, T.; Zhang, J.; Groom, S.; Sun, L.; Smyth, T.; Sathyendranath, S. Validation of MERIS Ocean-Color Products in the Bohai Sea: A Case Study for Turbid Coastal Waters. Remote Sens. Environ. 2010, 114, 2326-2336. [CrossRef]

33. Zhang, H.; Qiu, Z.; Sun, D.; Wang, S.; He, Y. Seasonal and Interannual Variability of Satellite-Derived Chlorophyll-a (2000-2012) in the Bohai Sea, China. Remote Sens. 2017, 9, 582. [CrossRef]

34. Zhou, Y.; Yu, D.; Yang, Q.; Pan, S.; Gai, Y.; Cheng, W.; Liu, X.; Tang, S. Variations of Water Transparency and Impact Factors in the Bohai and Yellow Seas from Satellite Observations. Remote Sens. 2021, 13, 514. [CrossRef]

35. Mao, Y.; Wang, S.; Qiu, Z.; Sun, D.; Bilal, M. Variations of Transparency Derived from GOCI in the Bohai Sea and the Yellow Sea. Opt. Express 2018, 26, 12191. [CrossRef] [PubMed]

36. Wang, Y.; Tian, X.; Gao, Z. Evolution of Satellite Derived Chlorophyll-a Trends in the Bohai and Yellow Seas during 2002-2018: Comparison between Linear and Nonlinear Trends. Estuar. Coast. Shelf Sci. 2021, 259, 107449. [CrossRef]

37. Zhai, F.; Wu, W.; Gu, Y.; Li, P.; Song, X.; Liu, P.; Liu, Z.; Chen, Y.; He, J. Interannual-Decadal Variation in Satellite-Derived Surface Chlorophyll-a Concentration in the Bohai Sea over the Past 16 Years. J. Mar. Syst. 2021, 215, 103496. [CrossRef]

38. Wu, Z.; Huang, N.E.; Long, S.R.; Peng, C.K. On the Trend, Detrending, and Variability of Nonlinear and Nonstationary Time Series. Proc. Natl. Acad. Sci. USA 2007, 104, 14889-14894. [CrossRef]

39. Zhang, L.; Xia, B.; Gui, Z.; Jiang, C. Contaminative Conditions Evaluation of Sixteen Main Rivers Flowing into Sea around Bohai Sea, in Summer of 2005. Environ. Sci. 2007, 28, 2409-2415. [CrossRef]

40. GB 12763.6-91; The Specification for Oceanographic Survey: Marine Biological Survey. Administration of Technology Supervision of China. China Standards Press: Beijing, China, 1991.

41. Pitarch, J.; Bellacicco, M.; Organelli, E.; Volpe, G.; Colella, S.; Vellucci, V.; Marullo, S. Retrieval of Particulate Backscattering Using Field and Satellite Radiometry: Assessment of the QAA Algorithm. Remote Sens. 2020, 12, 77. [CrossRef]

42. Cui, T.; Zhang, J.; Wang, K.; Wei, J.; Mu, B.; Ma, Y.; Zhu, J.; Liu, R.; Chen, X. Remote sensing of chlorophyll a concentration in turbid coastal waters based on a global optical water classification system. ISPRS J. Photogramm. Remote Sens. 2020, 163, 187-201. [CrossRef]

43. Al-Naimi, N.; Raitsos, D.E.; Ben-Hamadou, R.; Soliman, Y. Evaluation of satellite retrievals of chlorophyll-a in the Arabian Gulf. Remote Sens. 2017, 9, 301. [CrossRef] 
44. Hao, Q.; Chai, F.; Xiu, P.; Bai, Y.; Chen, J.; Liu, C.; Le, F.; Zhou, F. Spatial and temporal variation in chlorophyll a concentration in the Eastern China Seas based on a locally modified satellite dataset. Estuar. Coast. Shelf Sci. 2019, 220, 220-231. [CrossRef]

45. Harshada, D.; Raman, M.; Jayappa, K.S. Evaluation of the operational Chlorophyll-a product from global ocean colour sensors in the coastal waters, south-eastern Arabian Sea. Egypt. J. Remote Sens. Sp. Sci. 2021, 24, 769-786. [CrossRef]

46. Sá, C.; D’Alimonte, D.; Brito, A.C.; Kajiyama, T.; Mendes, C.R.; Vitorino, J.; Oliveira, P.B.; Da Silva, J.C.B.; Brotas, V. Validation of standard and alternative satellite ocean-color chlorophyll products off Western Iberia. Remote Sens. Environ. 2015, 168, 403-419. [CrossRef]

47. Pitarch, J.; Volpe, G.; Colella, S.; Krasemann, H.; Santoleri, R. Remote sensing of chlorophyll in the Baltic Sea at basin scale from 1997 to 2012 using merged multi-sensor data. Ocean Sci. 2016, 12, 379-389. [CrossRef]

48. Mélin, F.; Vantrepotte, V.; Chuprin, A.; Grant, W.; Jackson, T.; Sathyendranath, S. Assessing the fitness-for-purpose of satellite multi-mission ocean color climate data records: A protocol applied to OC-CCI chlorophyll-a data. Remote Sens. Environ. 2017, 203, 139-151. [CrossRef] [PubMed]

49. Brando, V.E.; Sammartino, M.; Colella, S.; Bracaglia, M.; Di Cicco, A.; D'Alimonte, D.; Kajiyama, T.; Kaitala, S.; Attila, J. Phytoplankton bloom dynamics in the baltic sea using a consistently reprocessed time series of multi-sensor reflectance and novel chlorophyll-a retrievals. Remote Sens. 2021, 13, 3071. [CrossRef]

50. He, X.; Bai, Y.; Pan, D.; Chen, C.T.A.; Cheng, Q.; Wang, D.; Gong, F. Satellite Views of the Seasonal and Interannual Variability of Phytoplankton Blooms in the Eastern China Seas over the Past 14 yr (1998-2011). Biogeosciences 2013, 10, 4721-4739. [CrossRef]

51. Lee, Z.; Carder, K.L.; Arnone, R.A. Deriving Inherent Optical Properties from Water Color: A Multiband Quasi-Analytical Algorithm for Optically Deep Waters. Appl. Opt. 2002, 41, 5755. [CrossRef]

52. Lee, Z.; Hu, C.; Shang, S.; Du, K.; Lewis, M.; Arnone, R.; Brewin, R. Penetration of UV-Visible Solar Radiation in the Global Oceans: Insights from Ocean Color Remote Sensing. J. Geophys. Res. Ocean. 2013, 118, 4241-4255. [CrossRef]

53. Seegers, B.N.; Stumpf, R.P.; Schaeffer, B.A.; Loftin, K.A.; Werdell, P.J. Performance Metrics for the Assessment of Satellite Data Products: An Ocean Color Case Study. Opt. Express. 2018, 26, 7404. [CrossRef]

54. Zhang, Y.; Pan, H.; Li, S.; Lv, X. Extracting Modulated Annual Cycle in Climate and Ocean Time Series Using an Enhanced Harmonic Analysis. Math. Probl. Eng. 2021, 2021, 9625795. [CrossRef]

55. Wu, Z.; Schneider, E.K.; Kirtman, B.P.; Sarachik, E.S.; Huang, N.E.; Tucker, C.J. The Modulated Annual Cycle: An Alternative Reference Frame for Climate Anomalies. Clim. Dyn. 2008, 31, 823-841. [CrossRef]

56. Ji, F.; Wu, Z.; Huang, J.; Chassignet, E.P. Evolution of Land Surface Air Temperature Trend. Nat. Clim. Chang. 2014, 4, 462-466. [CrossRef]

57. Morel, A.; Huot, Y.; Gentili, B.; Werdell, P.J.; Hooker, S.B.; Franz, B.A. Examining the Consistency of Products Derived from Various Ocean Color Sensors in Open Ocean (Case 1) Waters in the Perspective of a Multi-Sensor Approach. Remote Sens. Environ. 2007, 111, 69-88. [CrossRef]

58. Cheng, C.; Huang, H.; Liu, C.; Jiang, W. Challenges to the Representation of Suspended Sediment Transfer Using a DepthAveraged Flux. Earth Surf. Process. Landforms 2016, 41, 1337-1357. [CrossRef]

59. Gao, X.; Zhou, F.; Chen, C.T.A. Pollution status of the Bohai Sea: An overview of the environmental quality assessment related trace metals. Environ. Int. 2014, 62, 12-30. [CrossRef]

60. Lee, H.; Chao, S. A Climatological Description of Circulation in and around the East China Sea. Deep. Sea Res. Part II Top. Stud. Oceanogr. 2003, 50, 1065-1084. [CrossRef]

61. Chen, J.; Han, Q.; Chen, Y.; Li, Y. A Secchi Depth Algorithm Considering the Residual Error in Satellite Remote Sensing Reflectance Data. Remote Sens. 2019, 11, 1948. [CrossRef]

62. Carlson, R.E. A trophic state index for lakes. Limnol. Oceanogr. 1977, 22, 361-369. [CrossRef] 